\title{
Seismic performance of precast industrial facilities following major earthquakes in the Italian
} territory

\author{
A. Belleri ${ }^{1}$ \\ ${ }^{1}$ Department of Engineering, University of Bergamo \\ Viale Marconi 5, 24044 Dalmine, Italy \\ email: andrea.belleri@unibg.it \\ E. Brunesi $i^{2}$
}

${ }^{2}$ ROSE Programme, UME School, IUSS Pavia, Institute for Advanced Study

Via Ferrata 1, 27100 Pavia, Italy

email: emanuele.brunesi@eucentre.it

\begin{abstract}
R. Nascimbene ${ }^{3}$
${ }^{3}$ EUCENTRE, European Centre for Training and Research in Earthquake Engineering

Via Ferrata 1, 27100 Pavia, Italy

email: roberto.nascimbene@eucentre.it
\end{abstract}

\author{
M. Pagani ${ }^{4}$ \\ ${ }^{4}$ GEM, Global Earthquake Model
}

Via Ferrata 1, 27100 Pavia, Italy

email: marco.pagani@globalquakemodel.org

$$
\text { P. Riva }{ }^{5}
$$

${ }^{5}$ Department of Engineering, University of Bergamo

Viale Marconi 5, 24044 Dalmine, Italy

email: paolo.riva@unibg.it 


\begin{abstract}
Recent major earthquakes in the Italian territory have reaffirmed the seismic vulnerability of precast industrial buildings typical of the past Italian building practice, highlighting structural deficiencies observed during previous events and mostly related to the transfer of the horizontal forces between structural and non-structural elements. Intrinsic lack of shear and ductility capacity has been observed in simply supported beam-to-joist and beam-to-column connections, mainly constituted by vertical steel dowels or solely relying on shear friction, with or without neoprene pads. These connections were designed neglecting seismic loads and their premature failure was observed during the recent seismic events causing the loss of support of beam elements, due to elements relative movements, and the collapse of part of the buildings, mainly the roof.

The seismic displacement demand of the considered industrial buildings is larger compared to traditional reinforced concrete frame structures due to their higher flexibility, according both to higher inter-storey height and a cantilevered static scheme. Furthermore, this high flexibility could also result into displacement incompatibility between structural and non-structural elements, such as precast cladding panels, causing their connection failure.

On the basis of detailed field observations on a relevant number of buildings, collected just after the earthquakes, seven representative industrial facilities are examined to outline the main vulnerabilities of one-storey precast concrete structures not designed and detailed for seismic loads.
\end{abstract}

Keywords: Precast concrete structures; Connections; Field observations; Seismic vulnerability. 


\section{Introduction}

In Italy, the majority of the industrial one-storey and multi-storey facilities consists of reinforced concrete $(\mathrm{RC})$ precast structures. The use of precast concrete systems offers several advantages such as fast erection, lower investment prices and project costs due to prefabrication, higher allowance for quality controls, better sustainability and enhanced safety. However, the static scheme commonly adopted in the building construction market constitutes the major drawback of this structural typology. In fact the lateral-force resisting system (LFRS), traditionally composed of monolithic columns combined with pin-ended beams, is potentially characterized by significant flexibility and low shear strength and ductility capacity of the beam-to-column and panel-tostructure connections. The key role of the proper choice, design and detailing of the connection system is well-established in literature (fib 2003; Englekirk 2003; Khare et al. 2011; Magliulo et al. 2008; Bellotti et al. 2009; Negro and Toniolo 2012; Bournas et al. 2013) and extensive experimental campaigns were conducted considering typical precast structural layouts and connections based on monotonic and cyclic quasi-static tests (Rodriguez and Blandon 2005; Fishinger et al. 2008; Metelli et al. 2011; Belleri and Riva 2012; Psycharis and Mouzakis 2012a), pseudo-dynamic (Bournas et al. 2013) and shake-table tests (Psycharis and Mouzakis 2012b).

Besides this extensive research effort, it is currently accepted that the seismic response of other structural precast typologies, implying, for instance, the adoption of perimeter walls, re-centring post-tensioned connections (Priestley et al. 1999; Kurama 2000; Morgen and Kurama 2008; Holden et al. 2003; Schoettler et al. 2009; Belleri et al. 2013a; Fleischman et al. 2014) or equivalent monolithic structures (Pampanin and Park 2005; Restrepo et al. 1995), is more appropriate. However, although the recognised efficiency, these solutions were not pursued in Italy, as they result in increased on-site labour, longer time of construction and therefore increased cost. Furthermore, some LFRS solutions typically used for cast-in-place RC buildings, as braced systems and base isolation, may be ineffective for several precast structural configurations, the former due to the relevant heights and span lengths, the latter due to the high flexibility of the superstructure. 


\section{Past observation of failures}

During several past seismic events, conventional RC precast buildings have already suffered extensive damage, revealing their poor performance.

Iverson and Hawkins (1994) outlined the extensive collapses of the gravity columns in prefabricated garages, caused by the 1994 Northridge earthquake. The authors pointed out the gravity column inadequacy to accommodate the displacement demand induced by the LFRS, if not properly designed for it.

Field observations, collected by Muguruma et al. (1995) in the aftermath of the Kobe earthquake, highlighted severe collapses by soft-storey mechanisms of high-rise frame structures. These collapses were associated to the absence of seismic details, such as transverse reinforcement, and to the lack of regularity along the height of the building.

On site investigations explained the major structural deficiencies of RC precast industrial facilities, emerged from the 1998 Adana-Ceyhan (Adalier and Aydingun 2001) and 1999 Kocaeli and Duzce earthquakes (Saatcioglu et al. 2001; Sezen and Whittaker 2006), by means of inadequate stiffness and strength and/or problems caused by insufficient connections detailing.

More recently, the 2009 L'Aquila earthquake highlighted many cladding panels-related criticalities, confirming the need of considering panel-to-structure connection failures as a further limit state to be controlled in conventional design procedures (Toniolo and Colombo 2012; Bellotti et al. 2009). Similar deficiencies were observed by Ghosh and Cleland (2012), who reported connections failure between the cladding and the supporting structure during the 2010 Chilean earthquake. The majority of these panels are non-structural and their connections need to accommodate movement of the supporting structure to provide an efficient support. However, without the ability to accommodate relative displacement, cladding panels attract unintended forces, causing them to fall from the structure after connections failure. In addition, during the Chilean earthquake, damage occurred in industrial frame buildings with precast concrete cantilevered columns as LFRS, but its severity was mitigated by the use of wet-cast connections, allowing improved continuity of the 
secondary framing. This detail added some redundancy to the roof system and contributed to increase the overall structural integrity.

The Emilia earthquakes (Lauciani et al. 2012), May $20^{\text {th }}$ and $29^{\text {th }} 2012$, reaffirmed the seismic vulnerability of precast industrial buildings typical of the past Italian building practice. The majority of the precast buildings hit by the earthquakes suffered damage mainly related to the horizontal load transfer between structural and non-structural elements: inadequate connections between roof joists and supporting beams, beams and columns and between cladding panels and supporting elements. The present paper starts by describing the geological features of the Emilia seismic sequence. After an overview of the structural typologies hit by the earthquake and the evolution of the seismic requirements in the Italian Building Code, the paper shows the results of detailed field observations on a relevant number of industrial precast buildings collected just after the seismic sequence. Seven representative industrial facilities are examined to outline the main vulnerabilities of one-storey precast concrete structures not designed and detailed for seismic loads. The results reported herein are qualitative explanations of the observed failures. The presented observations could be useful for the design of new industrial facilities or retrofit interventions of existing structures, to address investigations in the aftermath of an earthquake and to address future research.

\section{A summary of past seismicity, seismic hazard and ground motions observed during the 2012 sequence}

The area stricken by the 2012 sequence is an area of intermediate seismicity in the Italian seismotectonic context, which produced over the last millennium earthquakes of moderate magnitude (i.e. $\mathrm{M}_{\mathrm{W}}<6.0$ ) as indicated in the Parametric Catalogue of Italian Earthquakes (Rovida et al. 2011). The most recent Italian national seismic hazard maps exhibit, in the area closer to the epicentres of the swarm, PGA values on rock with $10 \%$ probability of exceedance in 50 years around $0.125-0.15 \mathrm{~g}$ and of about $0.250-0.275 \mathrm{~g}$ for a $2 \%$ probability of exceedance in the same time interval (Gruppo di Lavoro 2004; Stucchi et al. 2011); following disaggregation analysis (see 
http://esse1.mi.ingv.it/, last accessed October 2013), the largest contribution to these values of hazard comes from earthquakes of magnitude close to $5.0 \mathrm{M}_{\mathrm{W}}$ occurring at short distances.

The 2012 main shocks fall within the seismogenic area 912 of the area source model (Meletti et al. 2008) used to compute the most recent national seismic hazard maps; these maps form the basis for the seismic actions defined in the current Italian Building code (D.M. 14/01/2008). The area source 912 is considered capable to generate earthquakes as large as $6.14 \mathrm{M}_{\mathrm{W}}$ (Gruppo di Lavoro 2004; Stucchi et al. 2011) in line with the characteristics and location of the two main earthquakes of 2012, occurred on May, $20^{\text {th }}\left(6.11 \mathrm{M}_{\mathrm{W}}\right.$ according to the European and Mediterranean Regional Centroid Moment Tensor Solution - RCMT - available at http://www.bo.ingv.it/RCMT/) and May $29^{\text {th }}\left(5.96 \mathrm{M}_{\mathrm{W}}, \mathrm{RCMT}\right)$.

Of particular importance from an engineering point of view are the characteristics of the shaking recorded during the 2012 sequence. Luzi et al. (2013) provide a comprehensive overview of strong motion data measured, emphasizing the remarkable presence of surface waves in a majority of the recorded acceleration time series as well as of very high values of the vertical component of the motion close to the ruptures. Energy distribution within the signals with respect to frequency is broadband at relatively short distances from the ruptures (i.e. approximately lower than 50/60 km) while at larger distances in the eastern portion of the Po plain, signals show a predominant peak in the spectrum around $0.2 \mathrm{~s}$, which is indicated by Luzi et al. (2013) as the possible fundamental frequency of the Plio-Quaternary alluvial deposits in the deepest part of the Po plain basin.

Meletti et al. (2013) performed a comparison between the hazard results of Stucchi et al. (2011) and strong-motion data produced by the sequence of earthquakes occurred in 2012. The comparison between the design code spectra for the horizontal component of motion computed for soil type C (D.M. 14/01/2008) and the recorded spectra at MRN (Mirandola) strong motion station, highlights a better match of the latter with the return design spectrum period of 2475 years. This observation roughly matches the recurrence interval defined by Stucchi et al. (2011) for the largest events generated by the area source encompassing the 2012 sequence. 


\section{Precast industrial buildings under investigation}

One-storey industrial buildings represent the most common form of precast construction in Northern Italy and the majority of the building stock severely damaged during the 2012 earthquakes. To clarify the genesis of the major structural deficiencies of the traditional RC precast facilities hit by the earthquakes, a brief introduction of the past and current design practice is presented followed by the typical structural layout of the considered buildings.

\section{Past and current design practice}

The current Italian building code (D.M. 14/01/2008), according to BS EN 1998 - 1:2004 (BSI 2005), prescribes the use of mechanical devices as connections between structural precast members, this prescription is mandatory in seismic areas since the mid-eighties (D.M. 3/12/1987) (Liberatore et al. 2013; Magliulo et al. 2013) and a standardized classification of the national seismicity dates back to 2004. Except in the case of some non-compulsory provisions, released between the midsixties and mid-seventies, the first specific seismic provisions appeared in early nineties and internationally recognized modern seismic concepts, as capacity design, were implemented only about ten years ago.

Though research efforts had been spent in investigating criticalities of precast concrete structures emerged from worldwide earthquakes (Englekirk 1982, 1990), the common design practice, at the time of construction of the considered damaged precast buildings, is essentially based on vertical static loads in combination with wind-induced and crane-induced horizontal loads. A horizontal load equal to $2 \%$ of the vertical load had anyway to be considered starting from 1987 . Therefore, although the prefabrication of RC elements in Italy is a consolidated technique, several industrial facilities left to shear-friction the horizontal load transfer mechanism of beam-to-column and beamto-floor connections, as they were built before 1987 or designed without the current seismic concepts and prescriptions. 
In the current precast design practice, for one-storey or low-rise industrial buildings of not primary importance, the contractors prefer to use dry connections as a seismic load transfer mechanism between precast elements in order to reduce the on-site construction time and cost related to emulative "wet" joints. In Emilia, as in the overall Italian context, the most advanced typology of shear-resisting dry beam-to-column joints is represented by pinned dowel connections with concrete corbels and 5-10 $\mathrm{mm}$ thick neoprene pads, potentially characterized by spalling of the concrete cover and brittle failures of the steel reinforcing bars un-grouted or partially grouted, as schematized in Fig. 1. As a result of this hinged frame structural layout, the seismic demand is currently accommodated by cantilevered columns with large cross-sections (up to 1000x1000mm in the case of three-storey buildings).

\section{Typical structural layout}

The considered damaged industrial buildings structural layout is characterized by cantilevered monolithic precast columns, placed into discrete socket foundations on-site grouted with low strength grout. No foundation-to-foundation structural links are provided to inhibit relative ground displacements. Pin-ended pre-stressed L-beams, inverted T-beams or double pitched beams are supported on column corbels or directly at the top of the columns.

According to the building code enforced at the time of construction, beam-to-column connections are based solely on friction, without additional mechanical devices; neoprene pads at the beamcolumn interface are in some cases adopted only for large spans. No secondary beams orthogonal to the primary frames are placed to ensure the three-dimensional response of these industrial buildings, substantially acting as a series of essentially two-dimensional portal frames, as shown in Fig. 2. The roof is formed by pre-stressed double-T beams, omega-beams or by proprietary micro-shed elements. 
To easily classify the seismic vulnerabilities experienced in such structural systems, the surveyed industrial buildings may be roughly distinguished into structures built between the seventies and the eighties (category A) and after the eighties (category B).

In particular, category A generally includes buildings with portal frames spaced 6 to $10 \mathrm{~m}$ centre to centre with 12-20 m long pre-stressed tapered prefabricated beams and 30-40 cm wide square RC columns. This layout results in slender columns; in addition no forks are provided at top of the columns to prevent the out-of-plane sliding or overturning of the supported beams. In the majority of the cases masonry walls were used to clad the perimeter of the structural skeleton.

Conversely, category B presents longer spans, up to $27 \mathrm{~m}$, covered by tapered I-beams which form gable roofs. As in category A, no moment continuity exists between beams and columns; the lateral load capacity of the structure is provided only by the cantilever action of the columns at the footings, which are not tied together. RC forks are provided at top of the columns as support of the beams but they are not designed to carry seismic induced lateral loads. Highly flexible roof diaphragms are the result of double-T pre-stressed joist or micro-sheds simply supported on the main beams with no mechanical connections. Both horizontal and vertical precast cladding panels are traditionally connected to the columns or to gutter beams by mechanical devices, typically anchor channels (Fig. 3).

Examples of the two structural typologies (category A and B) are shown in Fig. 4a and 4b respectively.

\section{Seismic vulnerabilities observed on site}

Lack of mechanical connections between the structural elements or connections unconservative design caused the most severe damages and failures during the Emilia seismic sequence. The inability of transferring the horizontal earthquake-induced actions led to the experienced loss of support of beams and joists. 
Inadequate design and detailing of ductile elements, deficient diaphragm effect, poor connection details and improper separation of non-structural elements are traditionally proven to be the major causes of non-seismically efficient response of conventional RC precast one-storey buildings in past events. Besides this, the extremely high flexibility of the considered precast buildings may modify the cantilevered static scheme conventionally assumed in the design process.

If compared to traditional cast in-place RC structures, precast hinged frames present a much more flexible static scheme and, in addition, the secant stiffness at yield may be significantly lower than the commonly adopted $50 \%$ reduction of the un-cracked cross-section due to the low axial load and to the large cross section resulting from second order effects limitations. In light of this, displacement demand, larger than predicted by conventional design tools and analysis methods, could induce interaction between structural elements and between structural and non-structural elements, causing their connection to fail (Belleri et al. 2013b).

In the aftermath of Emilia earthquakes, the European Centre for Training and Research in Earthquake Engineering (EUCENTRE) deployed field teams whose main observations were collected in a clearinghouse (http://www.eqclearinghouse.org/2012-05-20-italy/).

Out of the significant number of the structures surveyed, seven representative industrial facilities, whose main characteristics are summarized in Table 1, are selected to depict typical observed vulnerabilities and damage patterns of beam-to-column and roof-to-beam connections, cladding panels and columns.

\section{Beam-to-column and roof-to-beam connections vulnerability}

As mentioned before, the most severe damage observed during the Emilia earthquakes is associated to the structural element loss of support and consequent falling, since the beam-to-column and roofto-beam connections lacked mechanical devices as a seismic load transfer mechanism. Such type of collapse affected more significantly structures belonging to category A. Fig. 5 shows the loss of support of roof elements from the supporting beam, while Fig. 6 depicts the failure mode of a 
precast tapered I-beam due to its interaction with a column placed at the mid-span of the facade portal frame: designed as an element simply supported at its ends, the beam lost one of its supports during the earthquake and failed in flexure at mid-span, in accordance with a cantilevered static scheme not considered during design.

Although several cases of such collapses were observed in buildings of category B, relatively more complex motivations may be detected. Many partial collapses were experienced in such facilities due to roof elements drop, without evident damages in the columns, particularly in the presence of skylights, which increased the roof in-plane deformability. Such mechanisms were mainly localized in correspondence to building irregularities or in the perimeter portals, which are characterized by roughly halved tributary mass. In addition, some examples of precast member drop affected the central part of the buildings, where consecutive spans oscillated in opposition.

Qualitative explanation of such collapses, mostly due to the loss of support of the friction based connections, may be searched in the preliminary computations described in the following. Fig. 7(a) shows the elastic ADRS (acceleration displacement response spectrum) graphs (5\% relative damping) of the horizontal components, North-South (NS, solid line) and East-West (EW, dashed line), of the May $20^{\text {th }}$ event at Mirandola and the elastic ADRS graphs determined for two return periods, respectively 475 and 2475 years, in accordance with the current Italian Building Code (D.M. 14/01/2008). Fig. 7(b) shows a similar comparison regarding the vertical component. Mirandola, MRN according to the Italian RAN (Rete Accelerometrica Nazionale) network nomenclature, is chosen as it represents the station closest to the epicentre. The accelerograms recorded include site effects according to D.M. 14/01/2008: soil class C (180 m/s $\left.<V_{s}<360 \mathrm{~m} / \mathrm{s}\right)$ and no topographic amplification.

The comparison evidences that larger than "expected" acceleration and displacement demands are observed particularly in the range of period between $1 \mathrm{~s}$ and $2 \mathrm{~s}$, the typical range of fundamental periods for these flexible precast structures. In addition, the capacity-to-demand ratio is 
qualitatively estimated, by means of the safety factor (SF), in order to confirm the activation of the friction based mechanism of the connections during the event.

The aforementioned safety factor is computed as the ratio between shear friction capacity of the connection $\left(V_{R d}\right)$ and shear demand $\left(V_{E d}\right)$. The shear demand on the beam-to-column connection can be determined considering the tributary weight $\left(W_{i}\right)$ of each column, as the roof does not behave as a rigid diaphragm. The shear friction capacity is determined by accounting for the axial variation $( \pm \Delta N)$ due to the vertical component of the seismic action. $100 \%$ participating mass is assumed for the fundamental translational mode, while only $50 \%$ is considered in the vertical direction, due to a large fractioning of the vertical participating mass for such structures. The first mode in vertical direction $\left(T_{l V}\right)$ is assumed to vary between $1 / 4$ and $1 / 3$ of the fundamental translational mode $\left(T_{l H}\right)$ as confirmed by parametric eigenvalue analyses on this type of structures. Finally, the static friction coefficient $(\mu)$ used in this preliminary estimate ranges from 0.20 to 0.25 . The safety factor equation is:

$$
S F=\frac{V_{R d}}{V_{E d}}=\frac{\mu\left(W_{i} \pm \Delta N\right)}{W_{i} S_{a}\left(T_{1 H}\right) / g}=\frac{\mu\left(W_{i}-0.5 W_{i} S_{a}\left(T_{1 V}\right) / g\right)}{W_{i} S_{a}\left(T_{1 H}\right) / g}=\frac{\mu\left(1-0.5 S_{a}\left(T_{1 V}\right) / g\right)}{S_{a}\left(T_{1 H}\right) / g}
$$

Where $S_{a}\left(T_{1 H}\right)$ and $S_{a}\left(T_{1 V}\right)$ are the pseudo-acceleration spectrum values at the fundamental horizontal and first vertical periods respectively and $g$ is the acceleration of gravity.

Fig. 8(a) and (b) present the computed safety factor against the activation of the shear slippage at the beam-to-column connection level, by neglecting and considering the effect of the vertical component $( \pm \Delta N)$ respectively. Roughly $10 \%$ decay of SF is observed if the vertical component is included, thus confirming the not so prominent effect of the vertical component even though peaks larger than suggested by D.M. 14/01/2008 occurred during the 2012 Emilia seismic sequence.

Therefore, the variation of $S F$ in the period range of interest reveals the activation of an anticipated, non-dissipative slippage mechanism of the facing surfaces of the simply supported elements. In addition, seismic displacement demand approximately ranging from 13 to $20 \mathrm{~cm}$ seems to justify the loss of support experienced by the majority of the structures built between the seventies and the 
eighties, since the bearing length, traditionally provided and in-situ observed, is of the same order of magnitude $(10-15 \mathrm{~cm})$. Furthermore, even lower $S F$ can be potentially obtained by properly accounting for the combination of the two horizontal directions, as commonly assumed in current design practice. Further research is needed to confirm these preliminary observations.

Finally, highly flexible roofs were evidenced due to the absence of mechanical links between the joists and the extensive presence of skylights, sheds and micro-sheds. As a result, the seismic actions were directly transferred to the primary beams which in some cases exceeded their own outof-plane capacity and, hence, collapsed.

As in the case of the considered connections, the effects of the intrinsic structural deficiencies at the connection level are combined with a seismic input particularly severe in terms of displacement demand, which is to be reaffirmed as the key parameter to safely design and detail such precast structures.

\section{Cladding panels vulnerability}

Another frequent failure typology observed is the collapse of the cladding panels, consisting both of brick masonry and precast RC elements. For what concerns the former, traditionally used in buildings of category A, the incipient collapse was observed to be associated with the high out-ofplane slenderness, as no lateral restraint was provided in correspondence to columns and RC spandrels (Fig. 9).

It is observed that in the case of masonry cladding panels regularly distributed along the building perimeter with no significant openings, the panels provided sufficient in-plane strength to sustain the horizontal seismic loads, especially in the case of relatively stiff roofs. Nevertheless, in some cases, also structures with highly flexible roofs, unable to act as rigid diaphragms, presented undamaged masonry panels. By contrast, in the majority of the cases masonry panels were irregular along the height, due to the presence of ribbon glazing, without $\mathrm{RC}$ curbs at their top and with no connections to the columns. In these conditions the masonry panels experienced in-plane damage 
and in several cases out of plane overturning. The interaction between panels and adjacent columns will be discussed in the next section.

Conversely, in structures of category B, the observed falling of horizontal (Fig. 10) and vertical (Fig. 11) RC precast cladding panels was clearly related to failure in the mechanical connections, typically anchor channels and C-shape or L-shape steel profiles, to the supporting columns and/or beams. In fact, these devices were designed to sustain mainly vertical gravity loads and to avoid the panel overturning as a consequence of low out of plane horizontal actions, such as wind loads. During an earthquake these connections need to accommodate high relative displacements and rotations, being the displacement and rotation demand concentrated at the connection level owing its lower stiffness compared to the connected precast elements.

The complex panel-structure interaction caused many collapses particularly in the case of irregularities along the height of the structure. Many horizontal panels dropped down, as anchor channels were absolutely not adequate to allow for large seismic displacement demands and, consequently, their plasticization induced the expulsion of the retaining bolts by prying action, particularly in the upper panels. On the contrary, vertical panels behaved slightly better; if properly fixed to their foundation beam or drowned into the industrial pavement, they stiffened and strengthened the building, however without inhibiting the previously observed vulnerabilities. By contrast, collapses were observed in the case of vertical sandwich panels, adopted for thermal insulation issues, characterized by lower stiffness and strength.

Although retrofit solutions are beyond the purpose of the present paper, this seismic event seems to reaffirm the need of rationally conceived mechanical connectors to properly allow for displacement demand rather than try to make them work for unfeasible strain and load levels.

\section{Columns vulnerability}

Other damaged elements observed in Emilia are the columns. As depicted in Fig. 12 and 13, some columns lost their verticality due to permanent relative displacements and rotations experienced at 
the foundation level, where socket foundations not designed for seismic loading were provided without additional interconnecting tie beams.

The presence of industrial $\mathrm{RC}$ floors and the loss of roof elements and beams could have contributed to this phenomenon: the former in providing only mono-lateral restraint to the columns relative movements, the latter in reducing the stabilizing gravity load. Such foundation typology was widely used since the nineties and it was commonly designed against the overturning induced by wind loads and industrial cranes only. Furthermore, being the foundations under-designed for seismic loads, they most likely experienced elastic uplift, considering the reduced foot print and the relatively high foundation vertical load safety factor. Proofs of uplift are provided by $45^{\circ}$ cracks detected in the pavement in correspondence of the column edges.

Another column damage scenario is found in correspondence of ribbon glazing and cladding panels discontinuities where several stocky-column failures were noticed (Fig. 14). Furthermore, when RC forks were provided at the top of the columns, in more recent buildings, their flexural or shear capacities were clearly exceeded (Fig. 15), due to under-designed loads and poor detailing, therefore becoming ineffective in restraining the out-of-plane loss of the support.

More rarely, column base plastic hinges, with spalling of the concrete cover and/or buckling of the longitudinal reinforcement, was surveyed, especially in the case of flexible structures. In some cases, plastic hinges where observed in internal columns, characterized by flexural resistance significantly lower than external columns, being the former designed for vertical loads only and the latter for vertical and horizontal wind-induced loads. In addition the flexibility of the roof, increased by the presence of alternate skylights, led to seismic-induced loads in the central columns roughly doubled compared to external columns, which in turn were sometimes additionally stiffened and strengthened by vertical precast RC cladding panels. 


\section{Conclusions}

In light of the field observations collected in the aftermath of the 2012 Emilia seismic sequence, the present paper highlighted the surveyed seismic vulnerabilities of precast industrial facilities typical of the Italian context, in order to critically assess their observed poor performance if not designed and detailed as per modern seismic provisions. Both local and global collapses were depicted, categorized and preliminary examined by simplified computations. The analysis and proposal of efficient retrofit solutions are beyond the purpose of the paper. Additional research is needed to confirm the qualitative explanations provided in the paper.

The majority of precast structures did not perform acceptably, the number of fatalities and the amount of property loss were rather disproportionate compared to the intensity of the earthquakes. Most of the observed damage is related to the delay in the adoption and implementation of adequate seismic provisions, as well as to the mistrust towards new seismically efficient, but more complex, solutions.

Beam-to-column, roof-to-beam and panel-to-structure connections were reaffirmed to be the weak points of these systems, inhibiting a rational exploitation of the strength and ductility reserves of precast elements, usually observed to work elastically up to the connection failure. The failure modes experienced by such flexible structures, whose behaviour is generally governed by limiting the second order effects and controlling the displacement demand, were related to the loss of support of the horizontal primary elements, whose connection detailing was traditionally affected by speed of construction and relying solely on friction before the enforcement of recent building codes.

Lack of properly sized mechanical devices able to accommodate relative displacements and rotations caused severe damage to RC precast cladding panels. Out of plane overturning of masonry cladding panels was observed. More rarely, plastic hinges were detected at the base of the columns, which were mostly damaged by short column shear failures in correspondence to structural irregularities along the height of the building, such as ribbon glazing. 
The flexural and shear demand on existing RC forks at the top of the columns generally exceeded the capacity, leading to the inability of preventing the out-of-plane sliding and overturning of the framing beams. In addition, the columns were in some cases proven to rigidly rotate into the isolated socket foundations.

Highly-flexible roofs, realized with simply supported joists, did not act as rigid diaphragms, being unable to transfer and redistribute seismic forces into the vertical elements and to avoid critical differential displacements. As a consequence several element drops were detected.

Displacement incompatibility between structural and non-structural elements resulted into the complex interaction observed in the out-of-date gable frame systems. In these systems the lateral stability is totally based on the cantilever action of the columns and on the response of the columnto-foundation connection that in many cases was proven to be more flexible than the fixed-base restraint commonly assumed in the design process. In addition, the three-dimensional nature of the seismic motion was not accommodated by any orthogonal links between the two-dimensional portal frames and by properly sized tie beams interconnecting the discrete socket foundations.

\section{Acknowledgements}

The authors wish to express their gratitude to the Laboratories University Network of Seismic Engineering (ReLUIS) for the useful discussions from which many ideas on the development of the work have been gathered. The authors would also like to acknowledge the contribution of Dr. Davide Bolognini, Dr. Davide Bellotti and Dr. Mauro Torquati who collaborated on aspects related to the connections vulnerability.

\section{References}

Adalier, K., and Aydingun, O. (2001). "Structural engineering aspects of the June 27, 1998 AdanaCeyhan (Turkey) earthquake.” Engineering Structures, 23(4), 343-355. 
Belleri, A., and Riva, P. (2012). "Seismic performance and retrofit of precast grouted sleeve connections.” PCI Journal, 57(1), 97-109.

Belleri, A., Schoettler, M. J., Restrepo, J. I., and Fleischman, R. B. (2013a). "Dynamic behavior of rocking and hybrid cantilever walls in a precast concrete building.” ACI Structural Journal, in press.

Belleri, A., Torquati, M., and Riva, P. (2013b). "Seismic performance of ductile connections between precast beams and roof elements." Magazine of Concrete Research, DOI: 10.1680/macr.13.00092.

Bellotti, D., Bolognini, D., and Nascimbene, R. (2009). "Response of traditional RC precast structures under cyclic loading.” Environmental Semeiotics, 2(2), 63-79.

Bournas, D. A., Negro, P., and Molina, F. J. (2013). "Pseudodynamic tests on a full-scale 3-storey precast concrete building: Behavior of the mechanical connections and floor diaphragms." Engineering Structures, DOI: 10.1016/j.engstruct.2013.05.046.

Bournas, D. A., Negro, P., and Taucer, F. F. (2013). "Performance of industrial buildings during the Emilia earthquakes in Northern Italy and recommendations for their strengthening." Bulletin of Earthquake Engineering, DOI 10.1007/s10518-013-9466-z.

BSI (2005) BS EN 1998-1: 2004. Eurocode 8: Design of structures for earthquake resistance. Part 1: General rules, seismic actions and rules for buildings. BSI, London, UK

D.M. 3/12/1987, Italian Building Code (1987) - Norme tecniche per la progettazione, esecuzione e collaudo delle costruzioni prefabbricate. (in Italian)

D.M. 14/01/2008, Italian Building Code (2008) - Norme tecniche per le costruzioni. (in Italian)

Englekirk, R. E. (1982). “Overview of ATC seminar on design of prefabricated concrete buildings for earthquake loads.” PCI Journal, 27(1), 80-97.

Englekirk, R. E. (1990). “Seismic design considerations for precast concrete multistory buildings.” PCI Journal, 35(3), 40-51. 
Englekirk, R. E. (2003). "Seismic design of reinforced and precast concrete buildings.” Wiley \& Sons, New York.

fib, Bulletin 27 (2003). "Seismic design of precast concrete building structures.” 262 pages.

Fischinger, M., Kramar, M., and Isakovic, T. (2008). "Cyclic response of slender RC columns typical of precast industrial buildings." Bulletin of Earthquake Engineering, 6(3), 512-534.

Fleischman, R., Restrepo, J.I., Pampanin, S., Maffei, J.R., Seeber, K., and Zahn F.A. (2014). "Damage Evaluations of Precast Concrete Structures in the 2010-2011 New Zealand Earthquakes". Accepted paper for Earthquake Spectra.

Ghosh, S. K., and Cleland, N. (2012). "Observations from the February 27, 2010, earthquake in Chile.” PCI Journal, 57(1), 52-75.

Gruppo di Lavoro MPS (2004). "Redazione della mappa di pericolosità sismica prevista dall’Ordinanza PCM del 20 marzo 2003 n. 3274, All. 1.” Rapporto conclusivo per il Dipartimento della Protezione Civile, aprile 2004, Istituto Nazionale di Geofisica e Vulcanologia (INGV), Milano-Roma, Italy, available at http://zonesismiche.mi .ingv.it/ (last accessed October 2013), 163 pp. (in Italian).

Holden, T., Restrepo, J. I., and Mander, J. B. (2003). "Seismic performance of precast reinforced and prestressed concrete walls.” Journal of Structural Engineering, 129(3), 286-296.

Iverson, J. K., and Hawkins, N. M. (1994). "Performance of precast/prestressed concrete building structures during Northridge earthquake.” PCI Journal, 39(2), 38-56.

Khare, R. K., Maniyar, M. M., Uma, S. R., and Bidwai, V. B. (2011). "Seismic performance and design of precast concrete building structures: An overview." Journal of Structural Engineering (Madras), 38(3), 272-284.

Kurama, Y. C. (2000). "Seismic design of unbonded post-tensioned precast concrete walls with supplemental viscous damping." ACI Structural Journal, 97(4), 648-658.

Lauciani, V., Faenza, L., and Michelini, A. (2012). "ShakeMaps during the Emilia sequence." Annals of Geophysics, 55(4), 631-637. 
Liberatore, L., Sorrentino, L., Liberatore, D., and Decanini, L. D. (2013). "Failure of industrial structures induced by the Emilia (Italy) 2012 earthquakes." Engineering Failure Analysis, in press.

Luzi, L., Pacor, F., Ameri, G., Puglia, R., Burrato, P., Massa, M., Augliera. P., Franceschina, G., Lovati, S., and Castro, R. (2013). "Overview on the Strong-Motion Data Recorded during the May-June 2012 Emilia Seismic Sequence.” Seism. Res. Lett., 84(4), 629-644, doi: $10.1785 / 0220120154$.

Magliulo, G., Fabbrocino, G., and Manfredi, G. (2008). "Seismic assessment of existing precast industrial buildings using static and dynamic nonlinear analyses.” Engineering Structures, 30(9), 2580-2588.

Magliulo, G., Ercolino, M., Petrone, C., Coppola, O., and Manfredi, G. (2013). "Emilia Earthquake: the Seismic Performance of Precast RC Buildings.” Earthquake Spectra, in press.

Meletti, C., D'Amico, V., Ameri, G., Rovida, A., and Stucchi, M. (2013). "Seismic hazard in the Po Plain and the 2012 Emilia earthquakes.” Annals of Geophysics, 55(4), 623-629, doi: 10.4401/ag-6158.

Metelli, G., Beschi, C., and Riva, P. (2011). "Cyclic behaviour of a column to foundation joint for concrete precast structures." European Journal of Environmental and Civil Engineering, 15(9), 1297-1318.

Morgen, B. G., and Kurama, Y. C. (2008). "Seismic response evaluation of post-tensioned precast concrete frames with friction dampers." Journal of Structural Engineering, 134(1), 132-145.

Muguruma, H., Nishiyama, M., and Watanabe, F. (1995). "Lessons learned from the Kobe earthquake - a Japanese perspective.” PCI Journal, 40(4), 28-42.

Negro, P., and Toniolo, G. (2012) Design Guidelines for Connections of Precast Structures under Seismic Actions. Report EUR 25377 EN, European Commission

Pampanin, S., and Park, R. (2005). Appendix B: Special provisions for the seismic design of jointed ductile precast concrete connections. In NZS3101. 
Priestley, M. J. N., Sritharan, S., Conley, J. R., and Pampanin, S. (1999). "Preliminary results and conclusions from the PRESSS five-storey precast concrete test buildings." PCI Journal, 44(6), 42-67.

Psycharis, I. N., and Mouzakis, H. P. (2012a). "Shear resistance of pinned connections of precast members to monotonic and cyclic loading." Engineering Structures, 41, 413-427.

Psycharis, I. N., and Mouzakis, H. P. (2012b). "Assessment of the seismic design of precast frames with pinned connections from shaking table tests." Bulletin of Earthquake Engineering, 10(6), 1795-1817.

Restrepo, J. I., Park, R., and Buchanan, A. H. (1995). "Design of connections of earthquake resisting precast reinforced concrete perimeter frames.” PCI Journal, 40(5), 68-80.

Rodríguez, M., and Blandón, J. (2005). "Tests on a half-scale two-story seismic-resisting precast concrete building.” PCI Journal, 50(1), 94-114.

Rovida, A., Camassi, R., Gasperini, P., and Stucchi, M. editors (2011). "CPTI11, the 2011 Version of the Parametric Catalogue of Italian Earthquakes.” Milano, Bologna, http://emidius.mi.ingv.it/CPTI (last accessed October 2013).

Saatcioglu, M., Mitchell, D., Tinawi, R., Gardner, N. J., Gillies, A. G., Ghobarah, A., Anderson, D. L., and Lau, D. (2001). "The August 17, 1999 Kocaeli (Turkey) earthquake-damage to structures." Canadian Journal of Civil Engineering, 28(8), 715-773.

Schoettler, M. J., Belleri, A., Zhang, D., Restrepo, J. I., and Fleishman, R. B. (2009). "Preliminary results of the shake-table testing for the development of a diaphragm seismic design methodology.” PCI Journal, 54(1), 100-124.

Sezen, H., and Whittaker, A. S. (2006). "Seismic performance of industrial facilities affected by the 1999 Turkey earthquake." Journal of Performance of Constructed Facilities, 20(1), 28-36.

Stucchi, M., Meletti, C., Montaldo, V., Crowley, H., Calvi, G. M., and Boschi, E. (2011). “Seismic Hazard Assessment (2003-2009) for the Italian Building Code.” Bull. Seism. Soc. Am., 101(4), 1885-1911, doi: 10.1785/0120100130. 
Toniolo, G., and Colombo, A. (2012). "Precast concrete structures: the lessons learned from the L’Aquila earthquake.” Structural Concrete, 13: 73-83. 


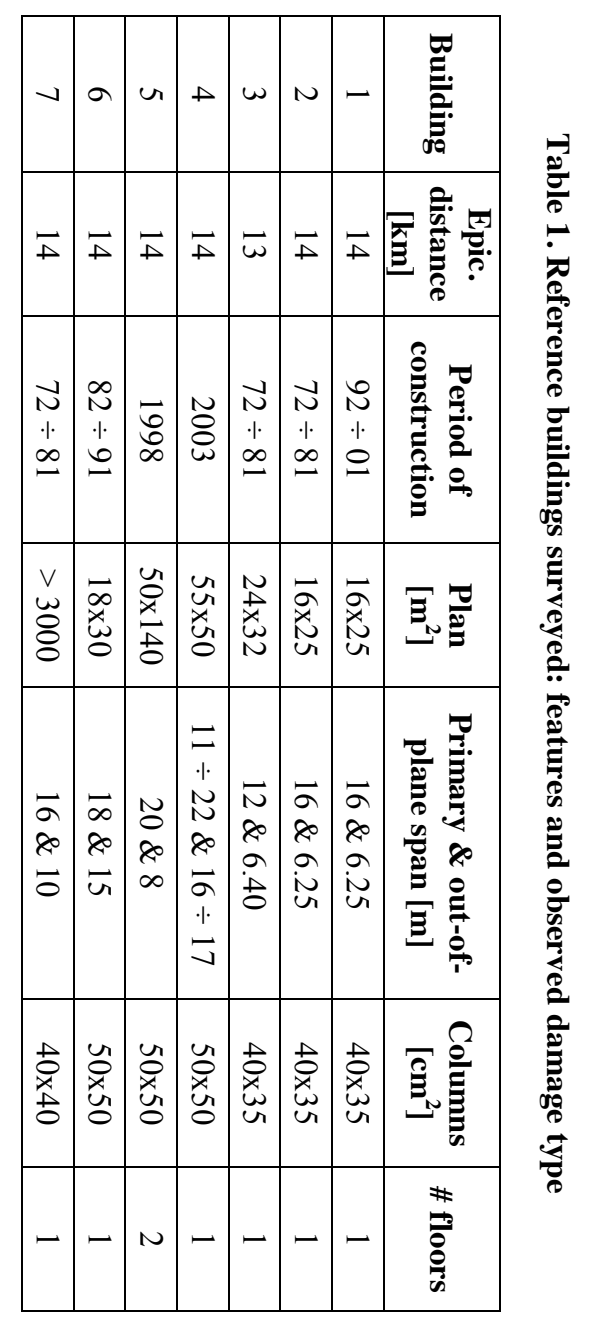




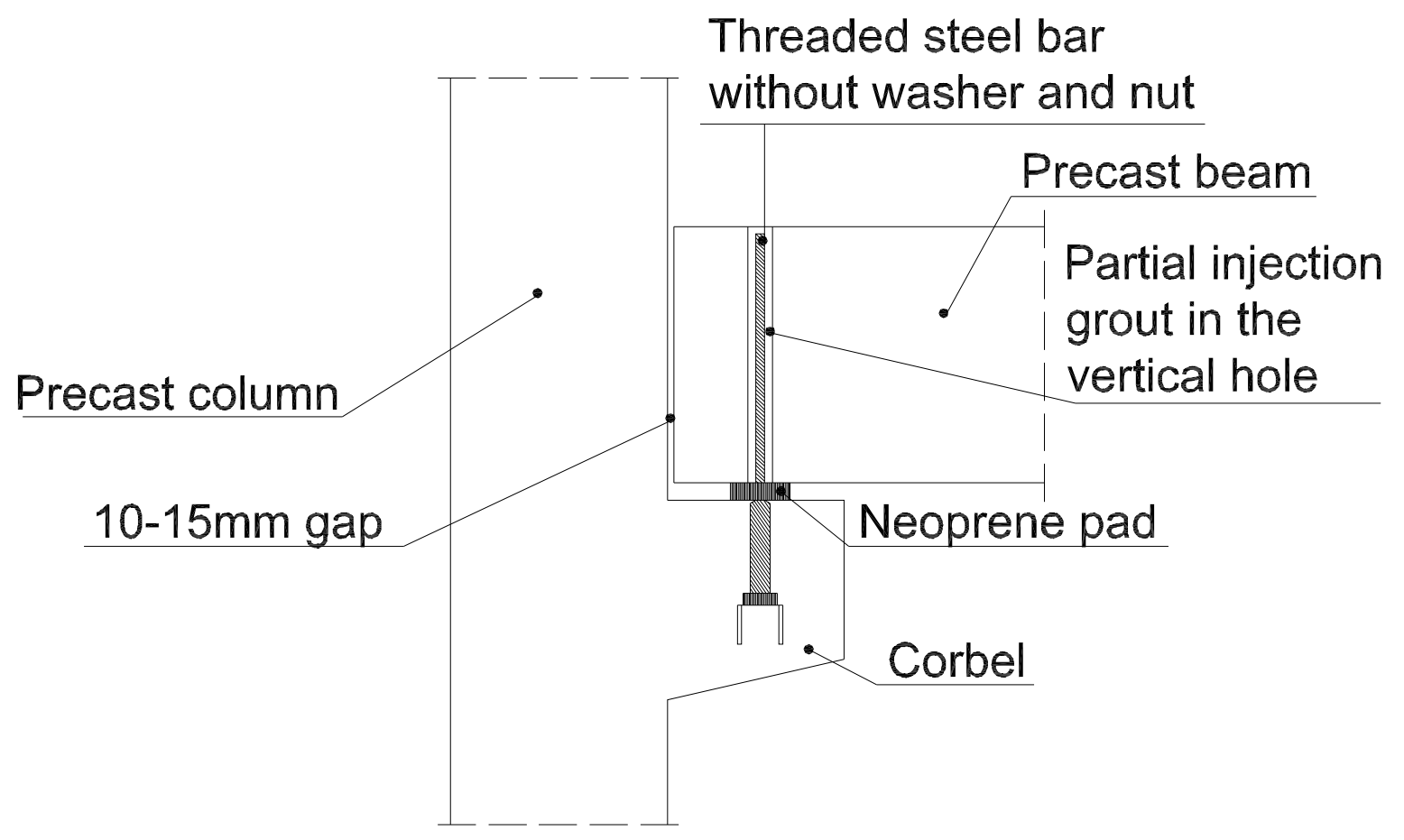




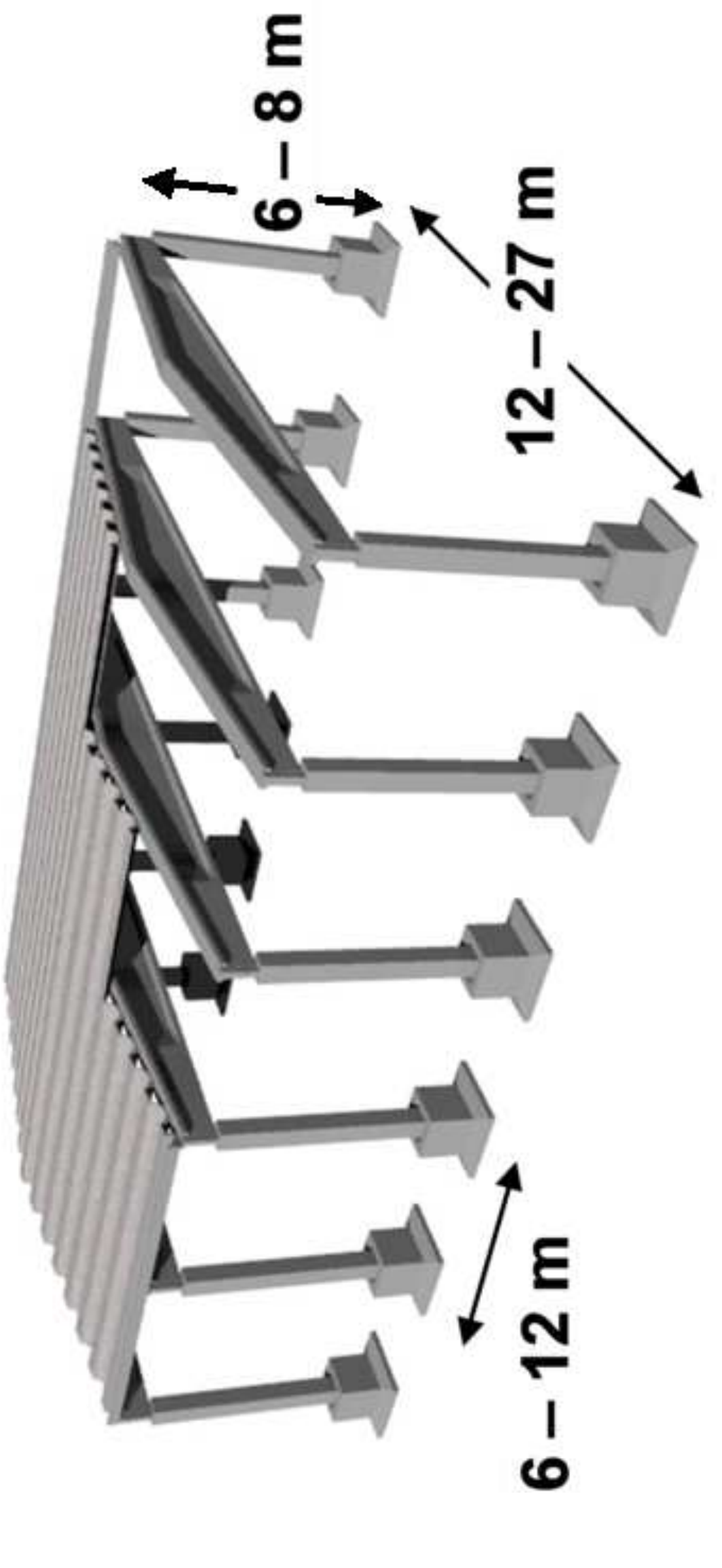


Figure 3

Click here to download Figure: Fig3.eps

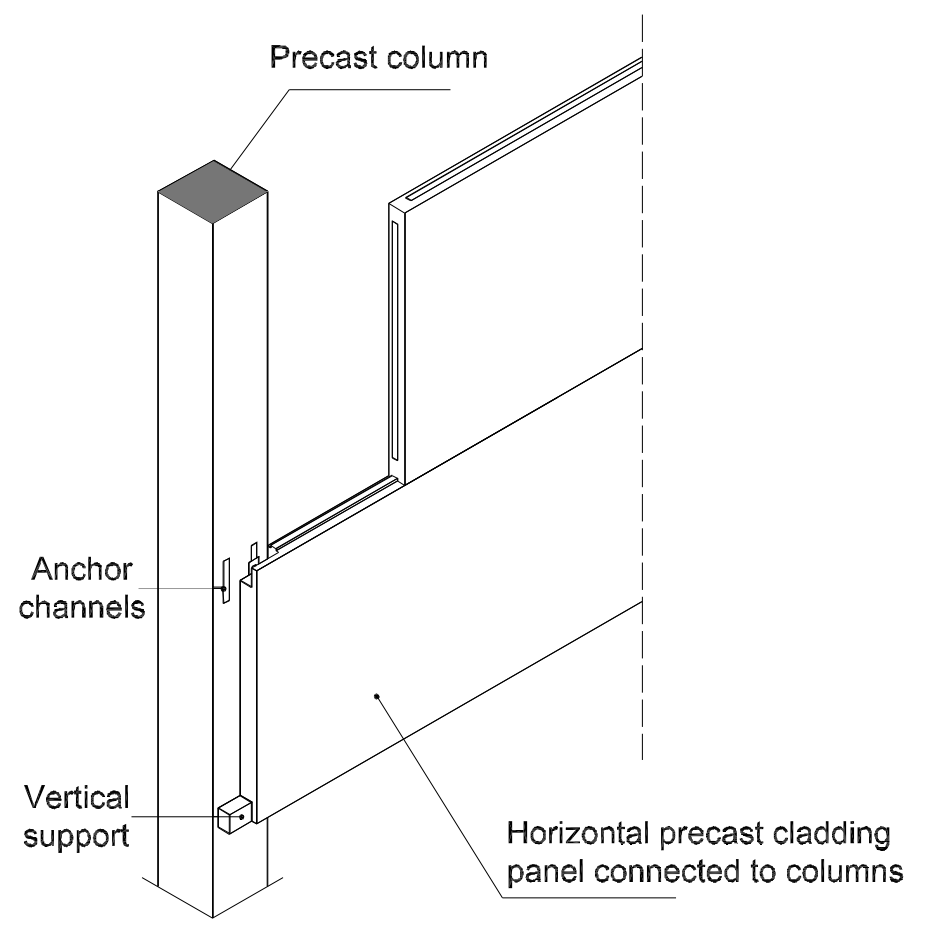




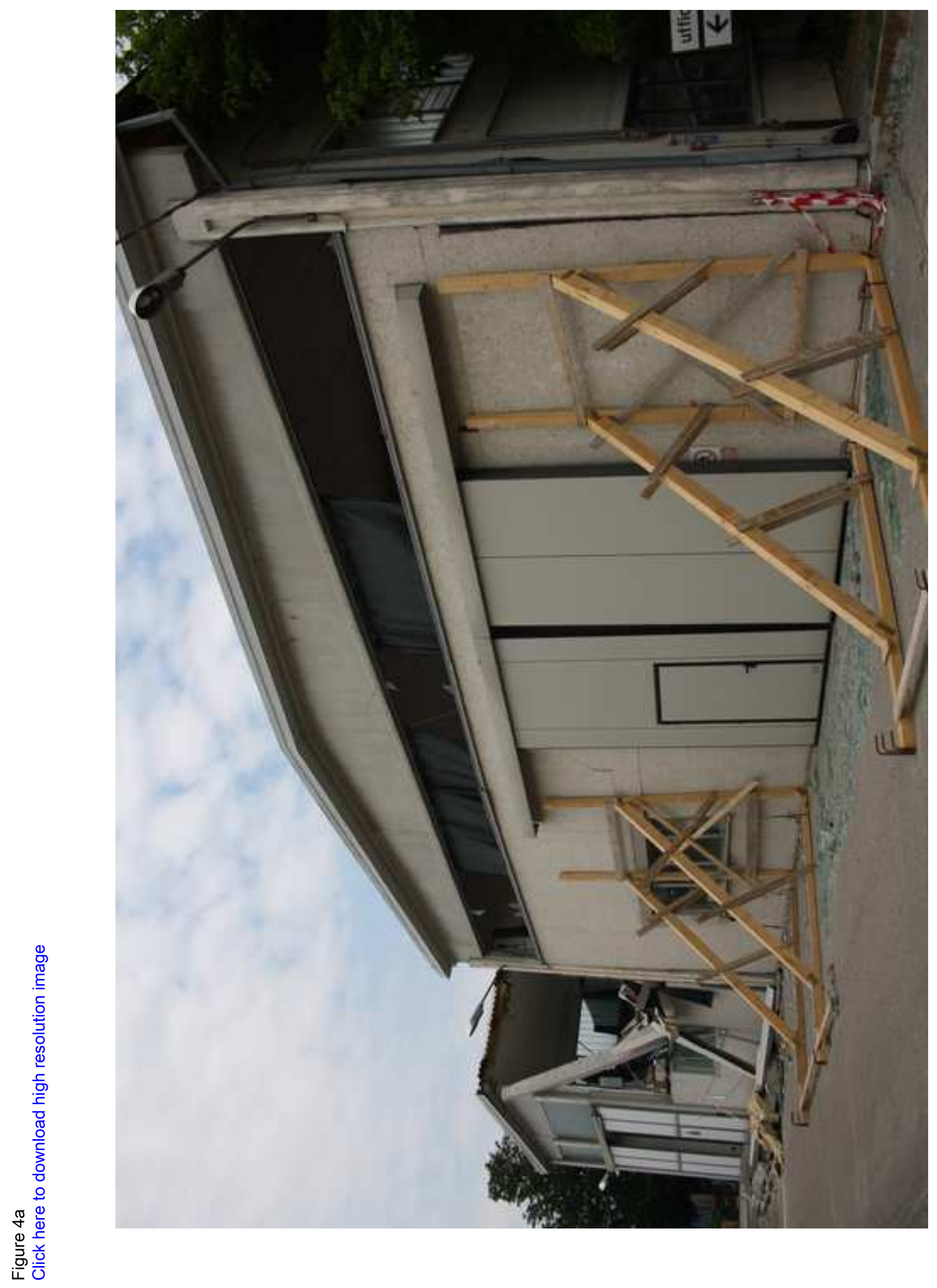




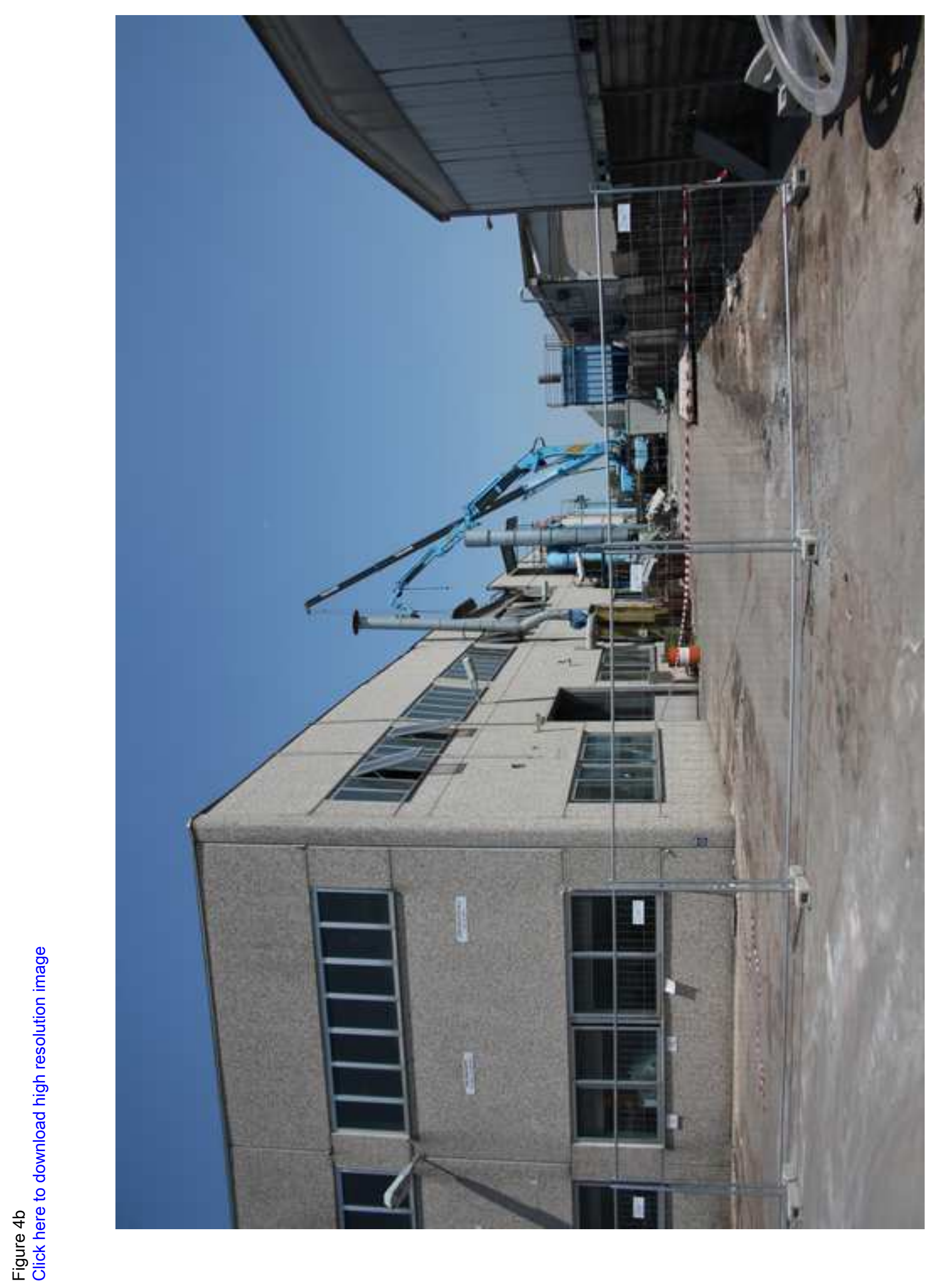




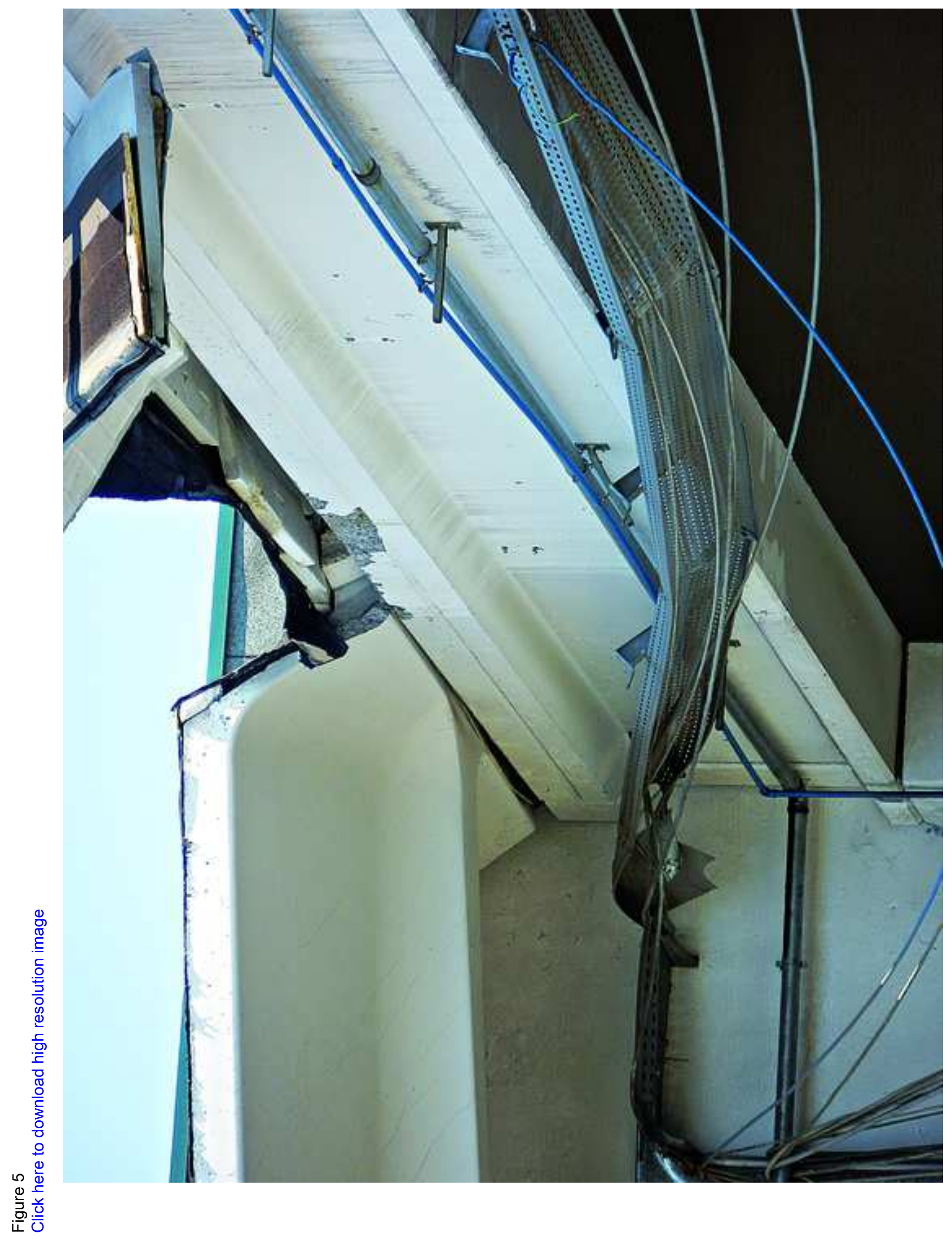




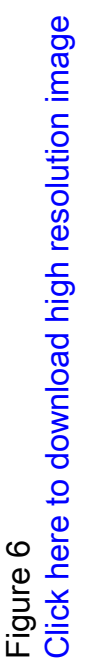

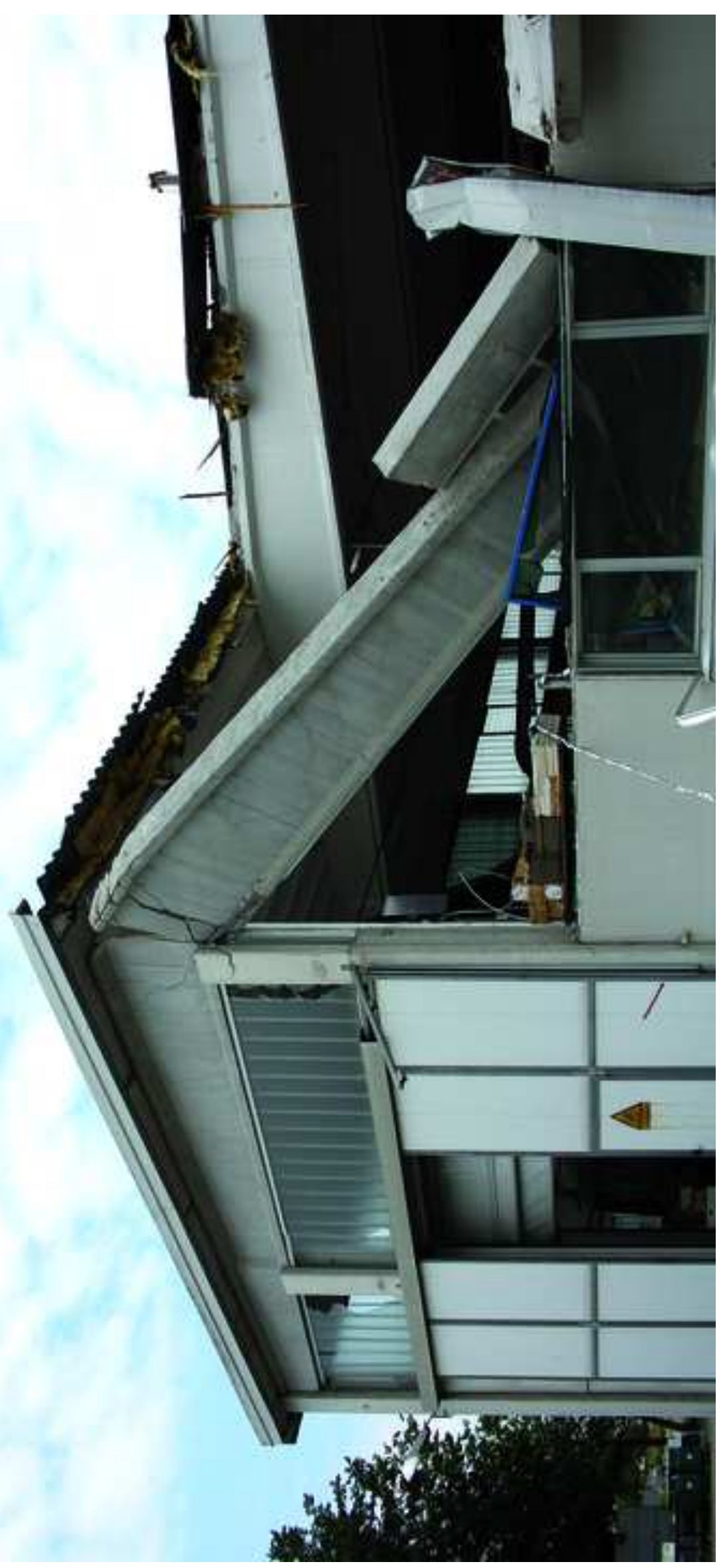


Click here to download Figure: Fig7a.eps

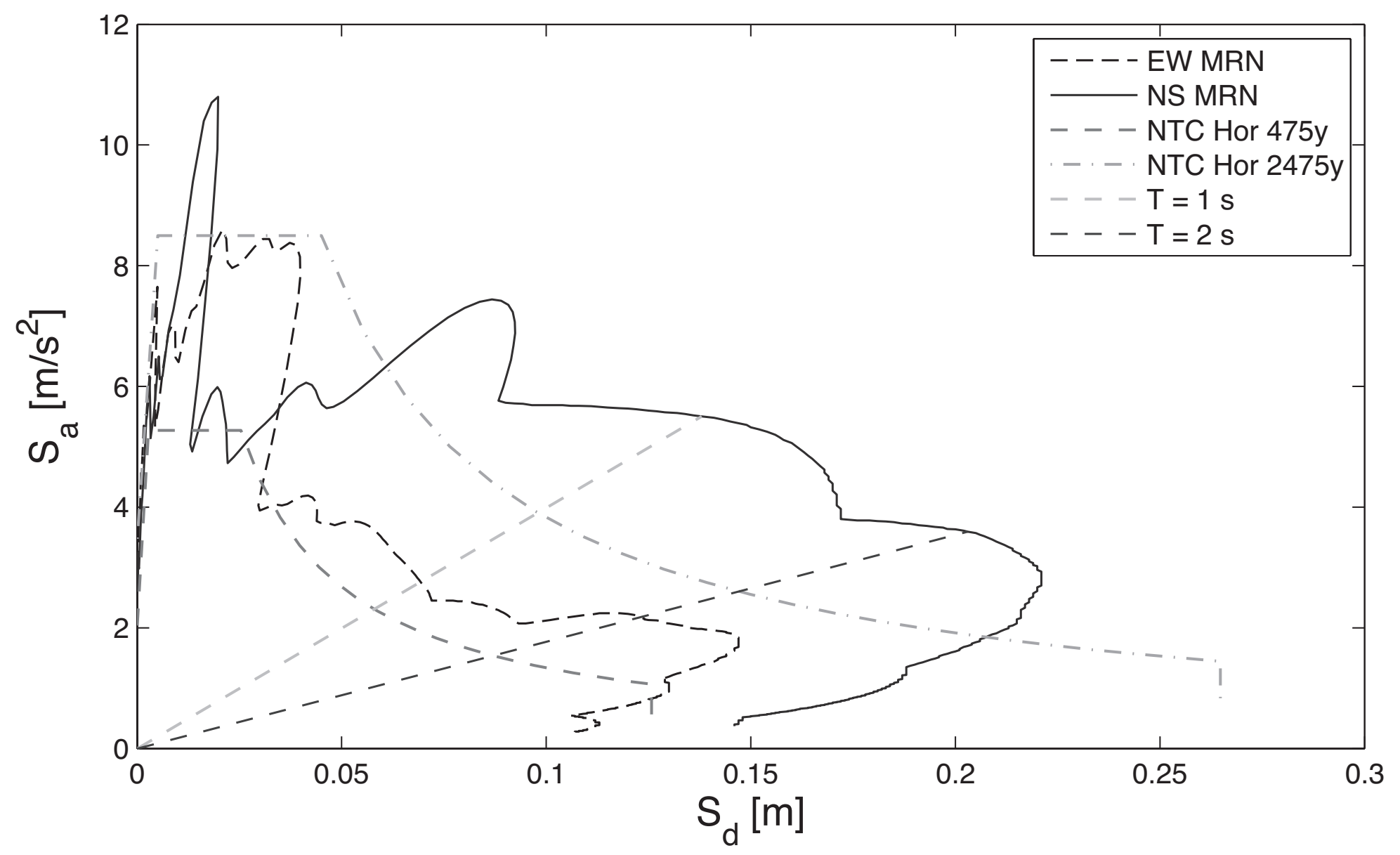


Figure $7 b$

Click here to download Figure: Fig7b.eps

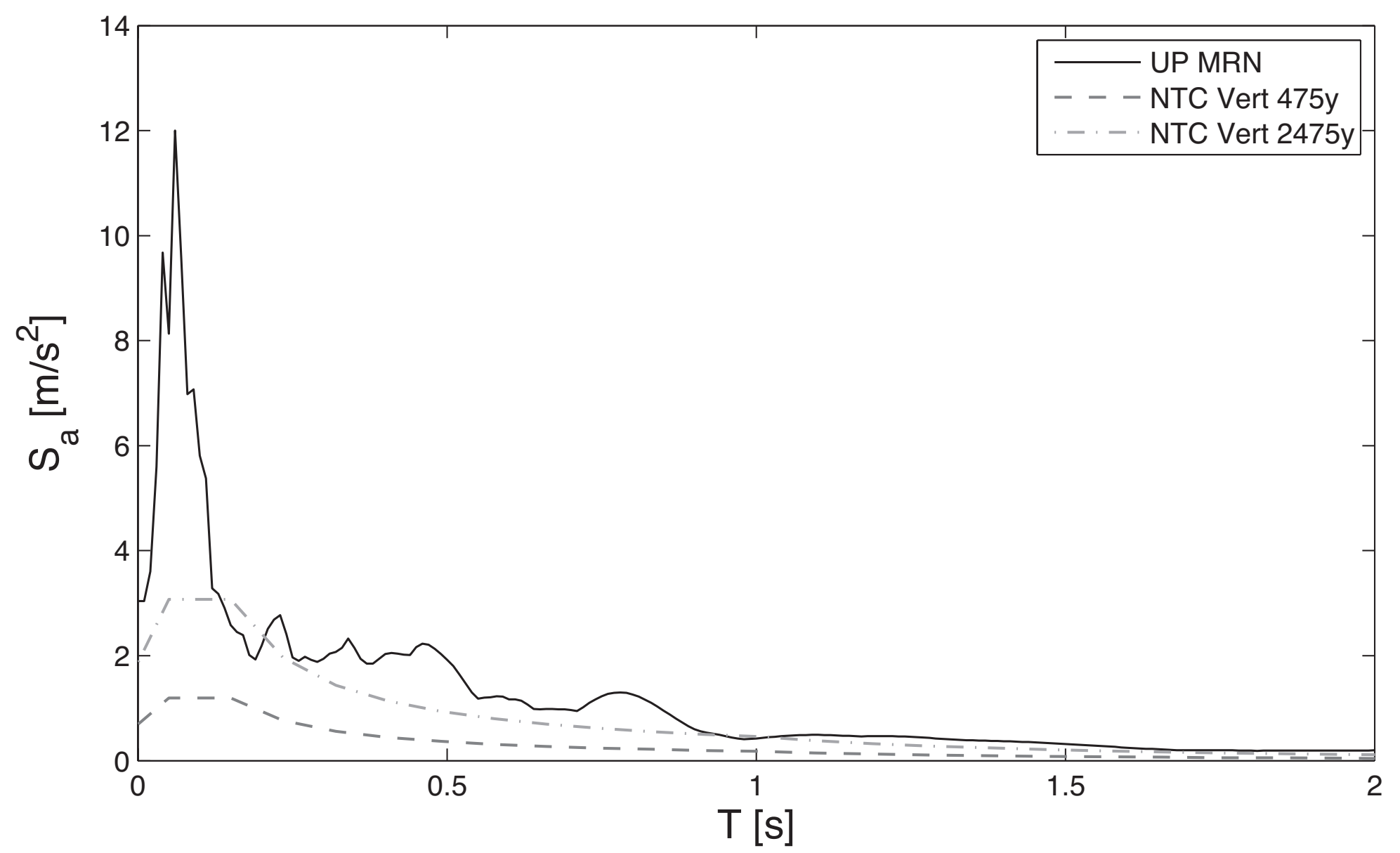


Click here to download Figure: Fig8a.eps

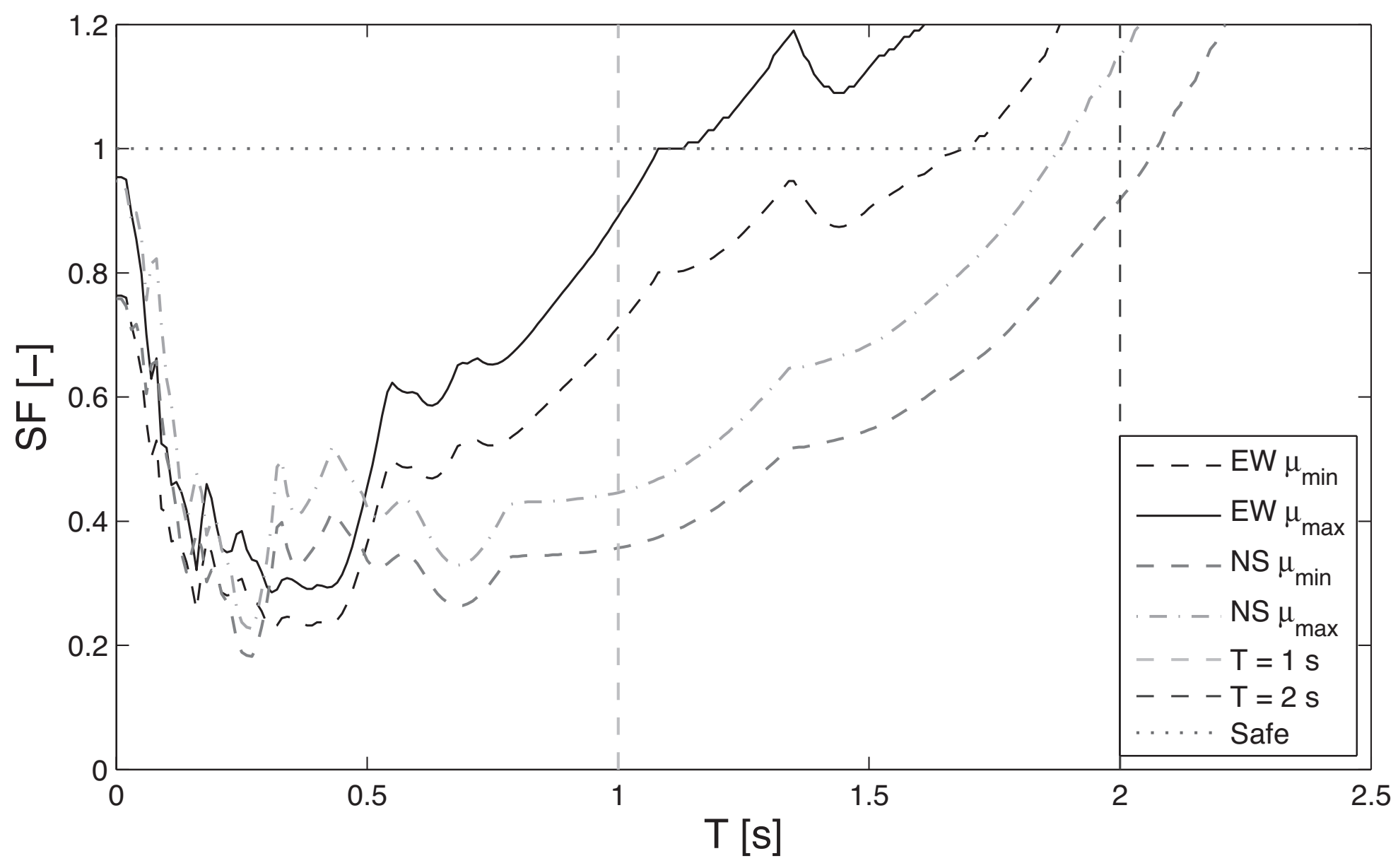


Figure 8b

Click here to download Figure: Fig8b.eps

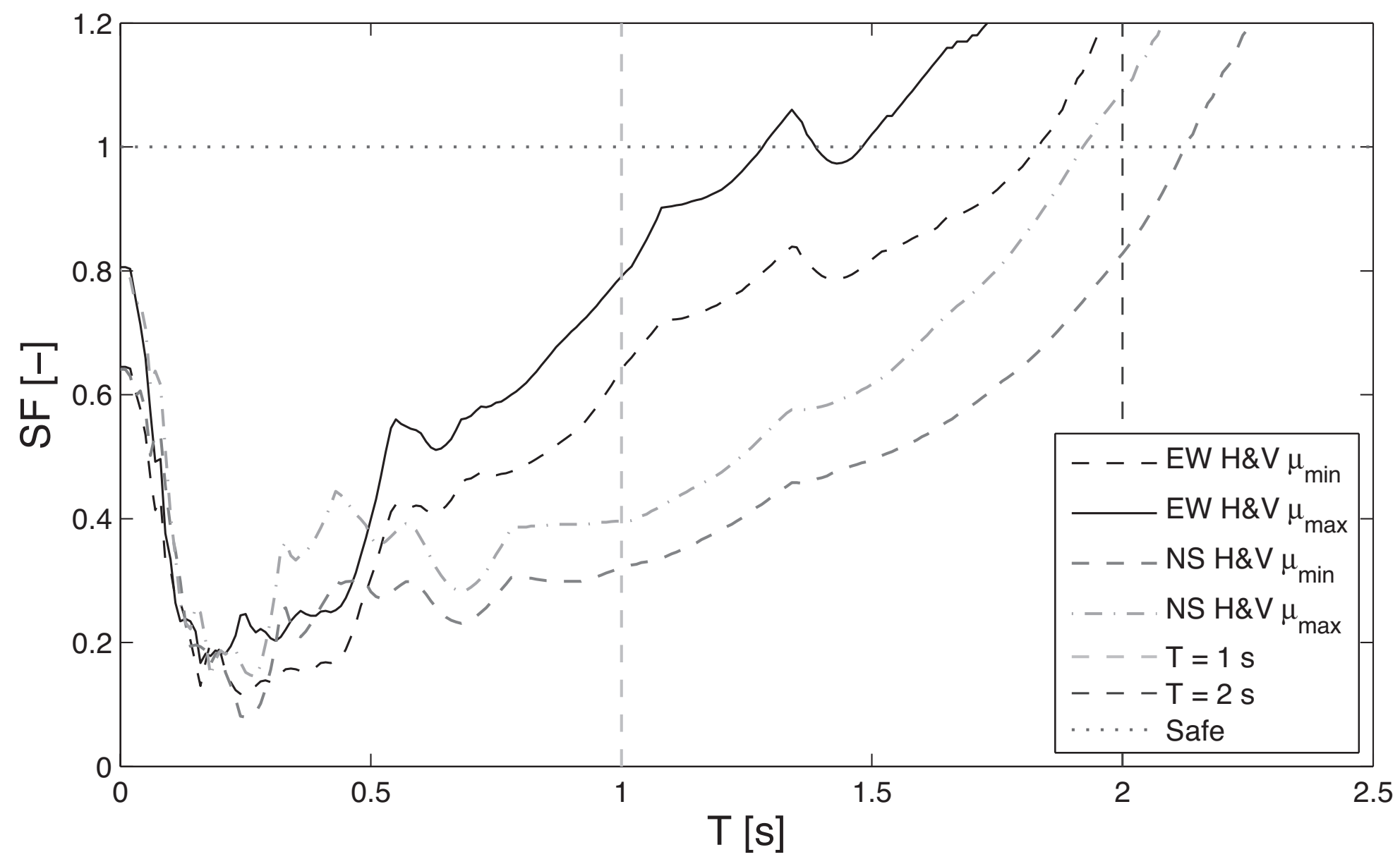




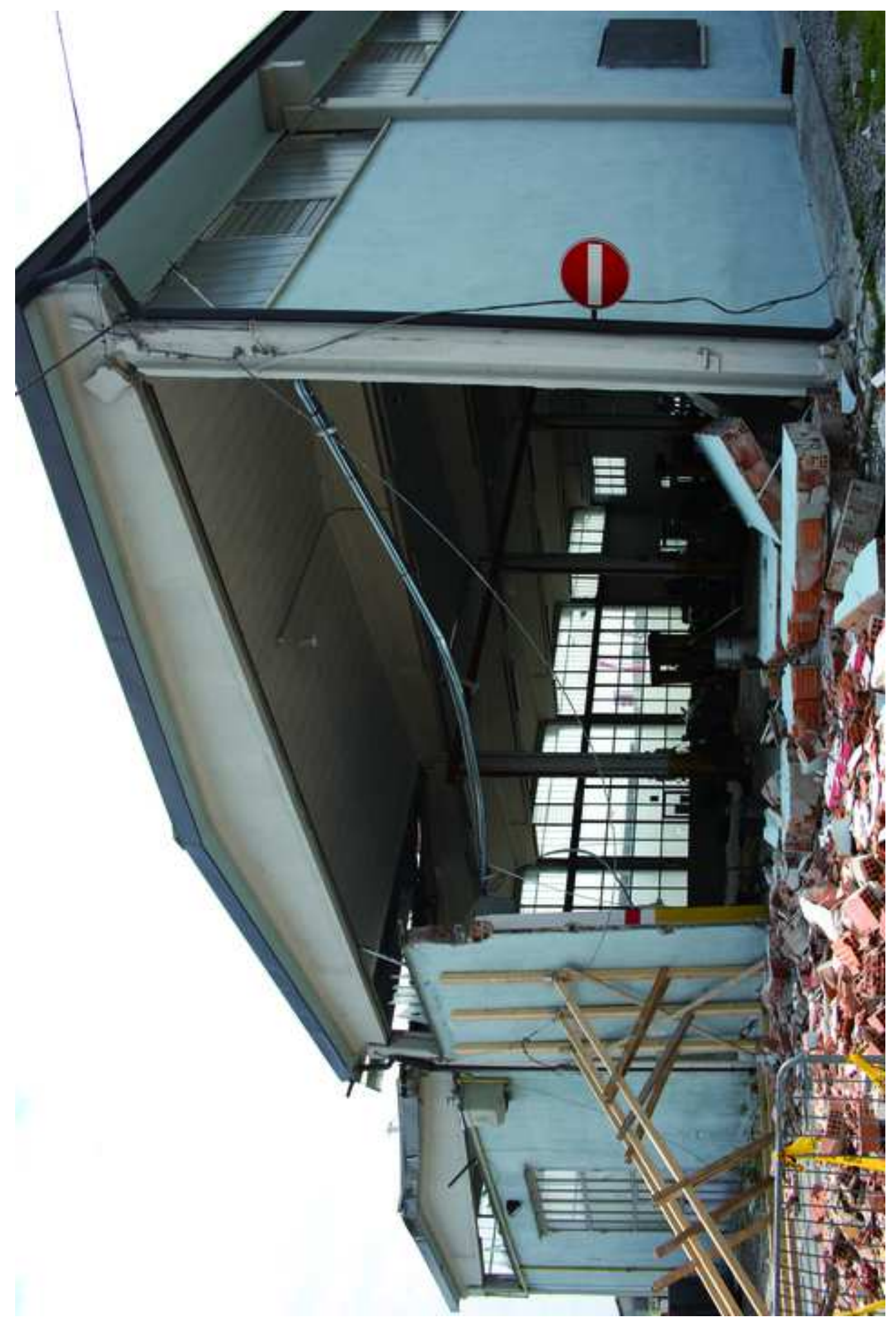




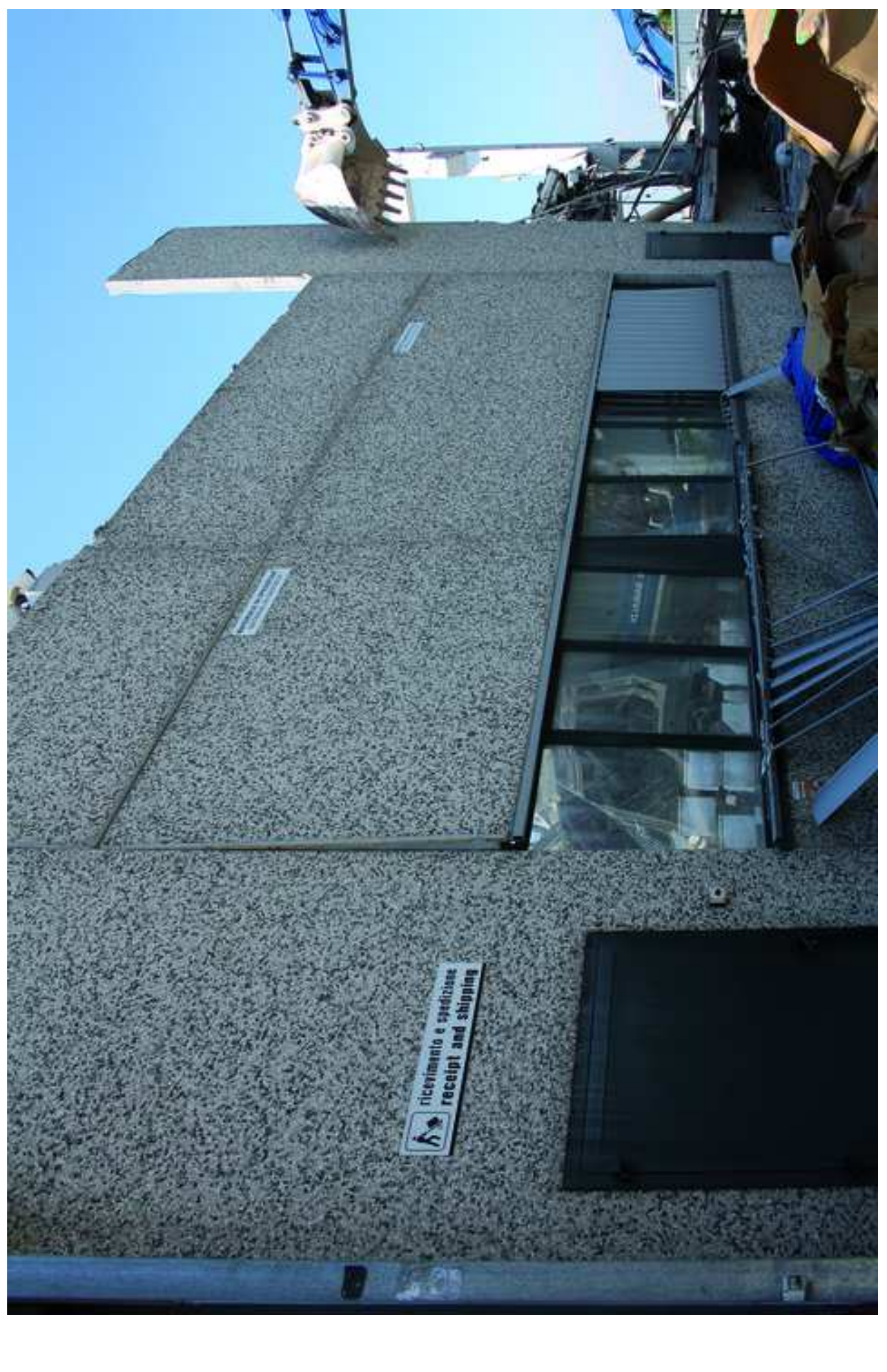


Figure 11

Click here to download high resolution image

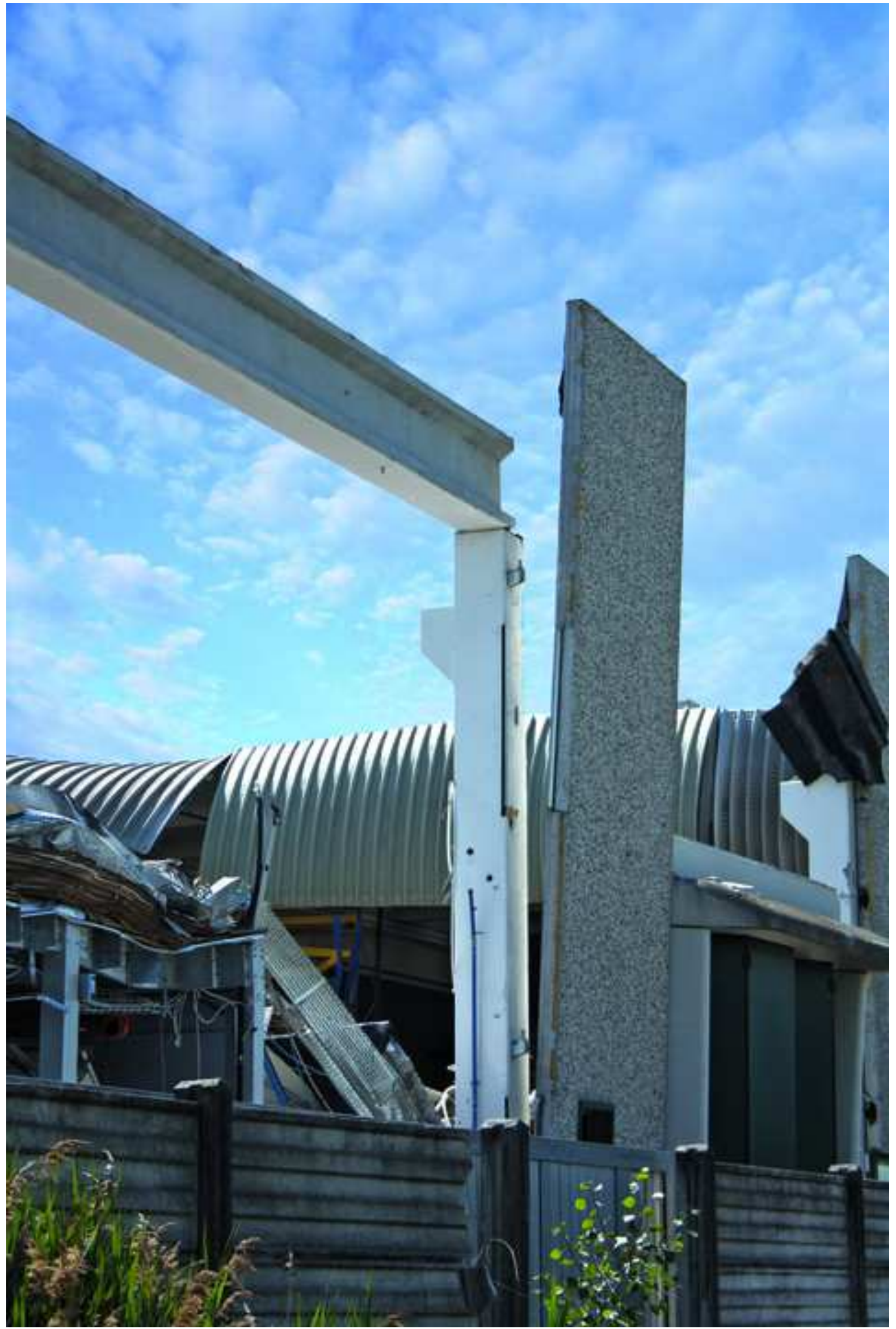


Figure 12

Click here to download high resolution image

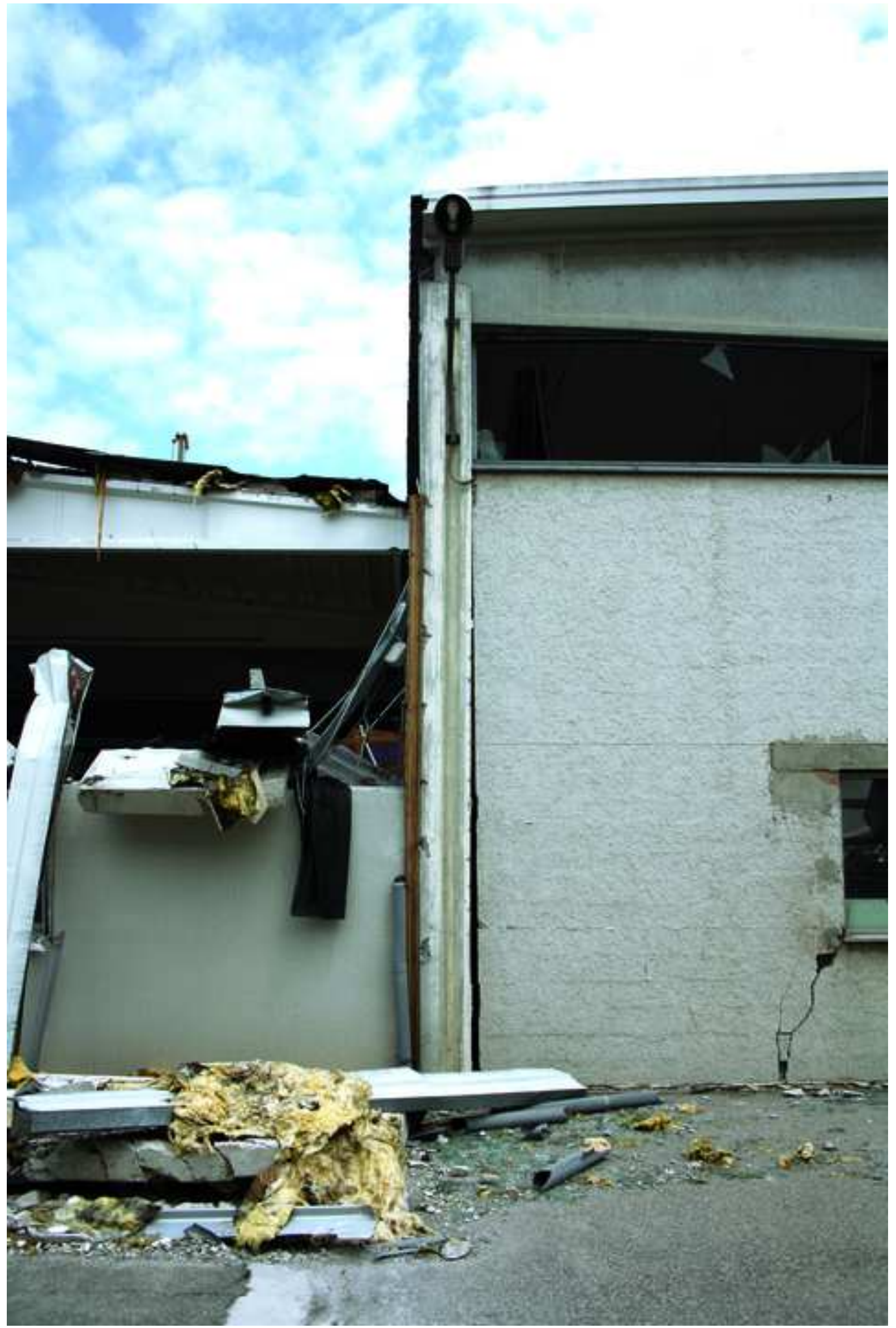




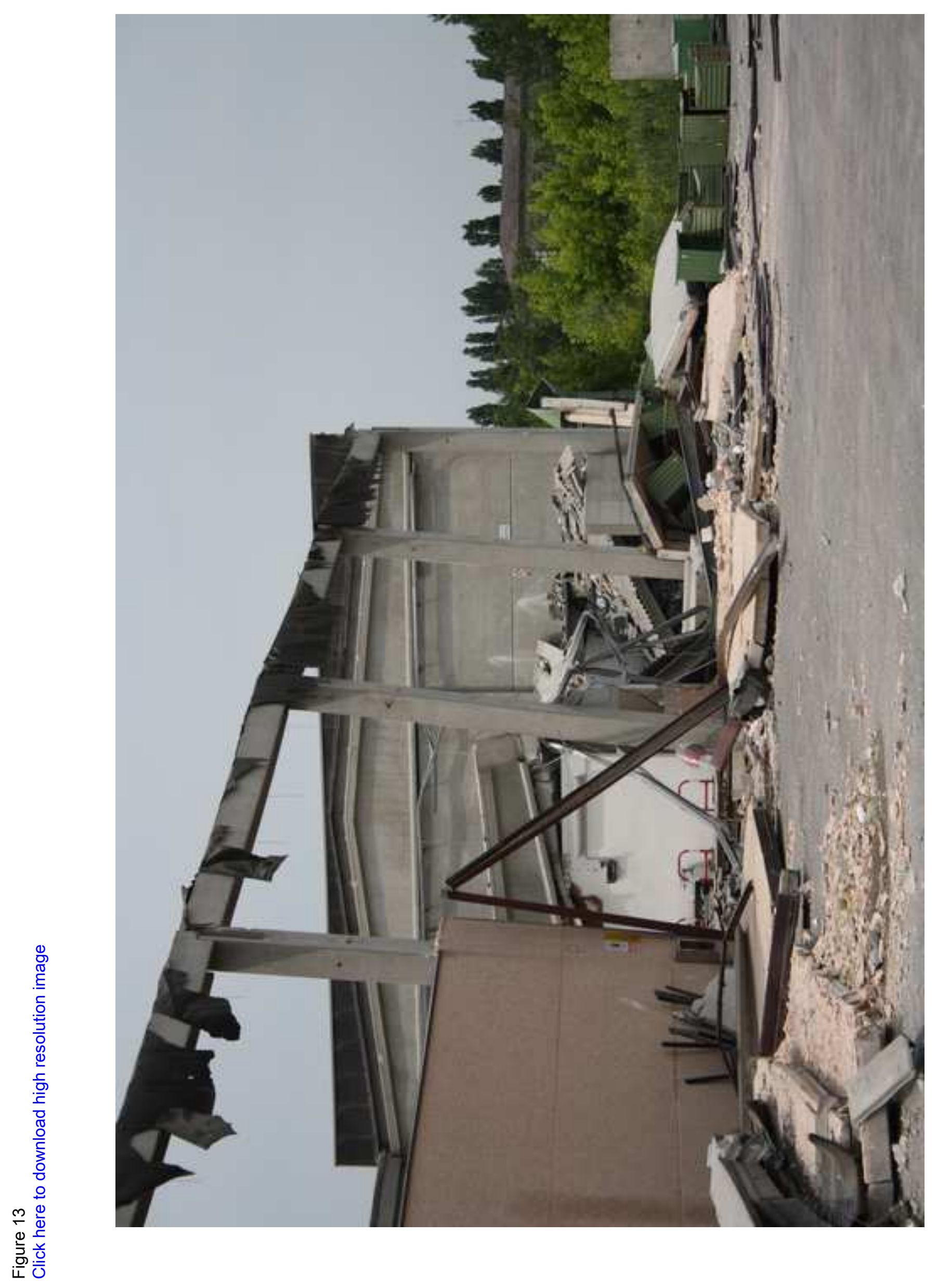


Figure 14

Click here to download high resolution image

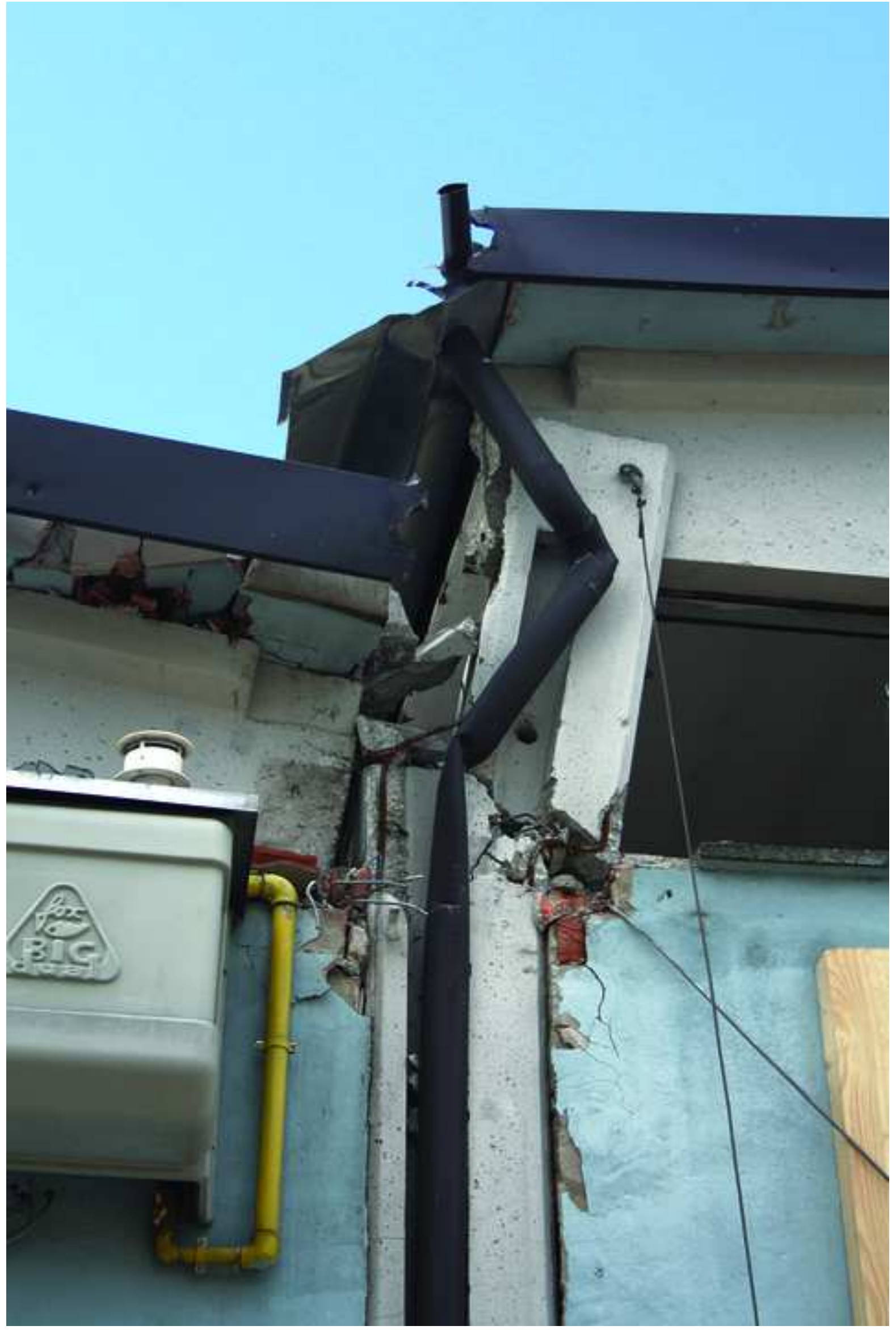




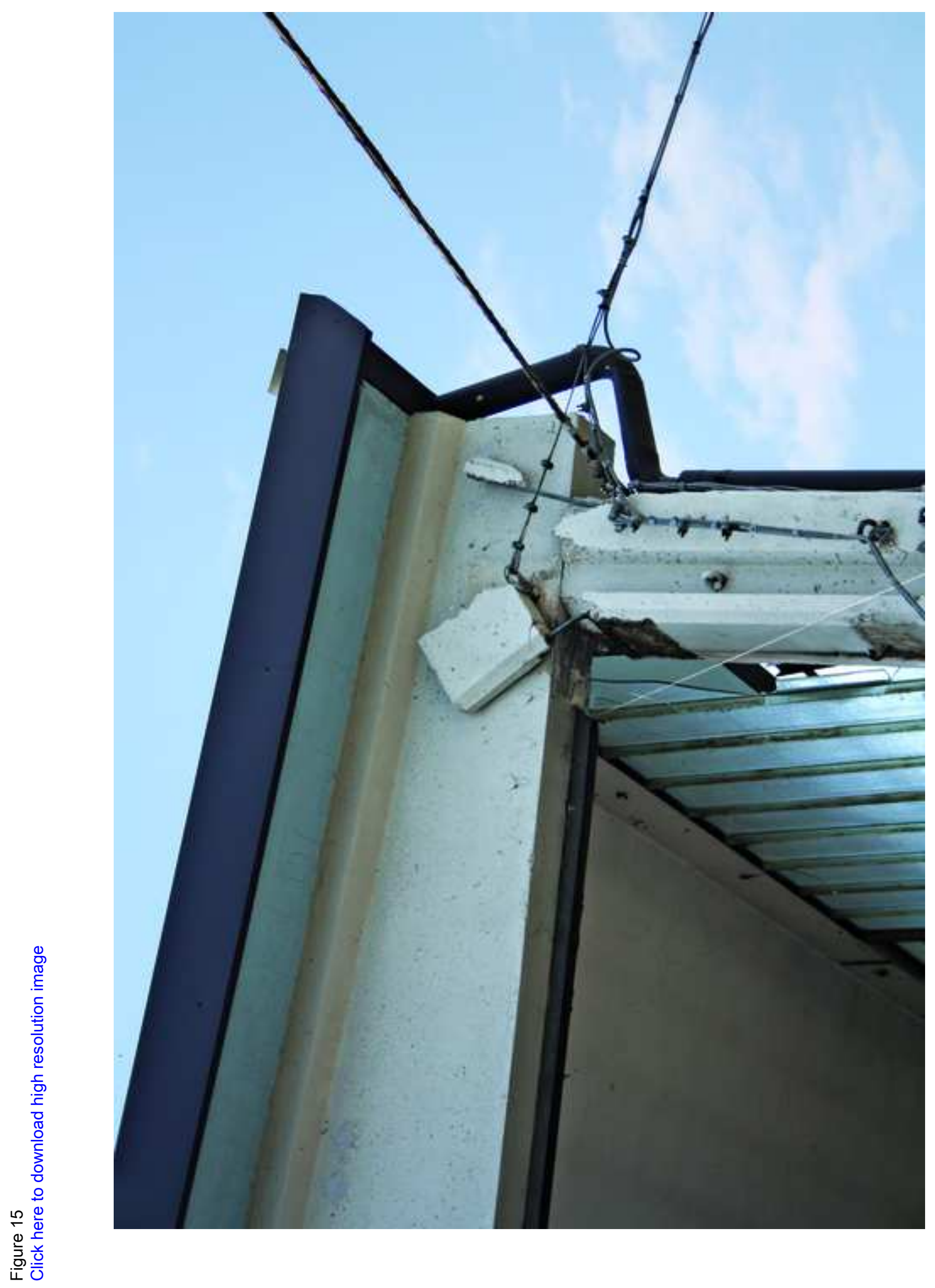




\section{Figure Captions:}

3 Fig. 1. Schematic of a typical pinned dowel connection with steel bars acting in shear

Fig. 2. Typical RC precast industrial building geometry

Fig. 3. Horizontal RC precast panel-to-column connection

9 Fig. 4. (a) Example of one-storey precast structure built between the 70's and the 80's; (b) Example of more recent one-storey precast structure with longer spans and precast cladding panels

Fig. 5. Roof element drop due to the loss of support

Fig. 6. Precast tapered I-beam failure due to the loss of support

Fig. 7. (a) Elastic ADRS graphs from recorded time histories (NS and EW) and in accordance with the Italian

17 building code (NTC). (b) Elastic pseudo-acceleration response spectra of the vertical component. Note: $\xi=5 \%$

Fig. 8. Variation of the SF against the activation of the shear slippage at the connection level, (a) by neglecting

20 and (b) considering the effect of the seismic vertical component

Fig. 9. Masonry cladding panels collapse

Fig. 10. Horizontal precast cladding panels collapse due to connection failure

Fig. 11. Vertical precast cladding panels collapse due to connection failure

Fig. 12. Loss of verticality in the column and relative permanent residual displacements and rotations 
30 Fig. 13. Permanent rigid rotation of the columns in the isolated socket foundations

31

32 Fig. 14. Stocky-column failure due to the ribbon glazing and cladding panels discontinuity along the height 33

34 Fig. 15. Collapse of the forks at the top of the columns due to out-of-plane actions 